\title{
Incorporating an iterative energy restraint for the Surface Energy Balance System (SEBS)
}

\author{
Evan Webster $^{\mathrm{a}, \mathrm{c}}$, Daniel Ramp ${ }^{\mathrm{a}, \mathrm{b}}$, Richard T. Kingsford ${ }^{\mathrm{a}}$ \\ ${ }^{a}$ Centre for Ecosystem Science, School of Biological, Earth and Environmental Sciences, University of New \\ South Wales, Sydney 2052 NSW, Australia \\ ${ }^{b}$ School of Life Sciences, University of Technology Sydney, Broadway 2007 NSW, Australia \\ ${ }^{c}$ Corresponding Author: Evan Webster, Centre for Ecosystem Science, School of Biological, Earth and \\ Environmental Sciences, University of New South Wales, Sydney 2052 NSW, Australia, ph: \\ +61293858295,f: +61293851558,e: e.webster@unsw.edu.au
}

\begin{abstract}
Keywords: Evapotranspiration, South-east Australia, Landsat, Surface Energy Balance, Surface Energy Balance System, Penman-Monteith, Triangular Energy Restraint
\end{abstract}

\section{Abstract}

The Surface Energy Balance System (SEBS) has proven itself as an effective remotely sensed estimator of actual evapotranspiration $\left(E T_{a}\right)$. However, it has several vulnerabilities 4 associated with the partitioning of the available energy $(A E)$ at the land surface. We intro- 


\section{Introduction}

Evapotranspiration $(E T)$ is a critical process for water accounting in catchment areas (Glenn et al., 2011), driving current and future water yields for urban populations (Chiew and McMahon, 2002; McVicar et al., 2012). It represents complex interactions involving moisture availability and transpiration, influenced by wind, temperature, heat fluxes, and surface roughness (Kalma et al., 2008). Estimating actual evapotranspiration $\left(E T_{a}\right)$ and understanding how it varies spatially and temporally is essential for quantifying water loss across complex heterogeneous catchments (Glenn et al., 2011). Water planning authorities often rely on $E T_{a}$ measurements from a few isolated ground flux towers or calculations of potential evapotranspiration $\left(E T_{o}\right)$ (Monteith, 1965; Priestley and Taylor, 1972) or reference evapotranspiration $\left(E T_{r}\right)$ (Allen et al., 1998) from one or more nearby meteorological ground stations. Estimations of catchment evaporative water loss and water yield are also complicated by patchy or non existent stream flow records (Winsemius et al., 2009), arising from substantial infrastructure costs or logistical difficulties. So, water accounting through hydrological models is often limited by the reliance on incomplete datasets (Merz et al., 2011; Winsemius et al., 2009), including relatively poor estimation of $E T_{a}$ and $E T_{o}$. Satellite remote sensing techniques can reduce uncertainty within these inputs in hydrological models (Immerzeel and Droogers, 2008; Yin et al., 2016) through estimations of fine scale spatially explicit $E T_{a}$ throughout catchments, improving water accounting for urban populations.

Remotely sensed thermal imagery and its estimation of surface temperature $\left(T_{S}, K\right)$ is a critical component in surface energy balance (SEB) algorithms (Evett et al., 2012; Kalma et al., 2008) for the calculation of spatially explicit $E T_{a}$ at landscape $(\approx 30 \mathrm{~m})$ or regional (250 $m-1 \mathrm{~km})$ scales. While spaceborne instruments like the Advanced Very High Resolution Radiometer (AVHRR) and the Moderate resolution Imaging Spectrometer (MODIS) can provide provide high temporal frequency $E T_{a}$ assessments at regional, continental, or global scales (Kalma et al., 2008; Mu et al., 2011), significant $E T_{a}$ variability is often present in agricultural or forested landscapes at a few hundred meters or less (Anderson et al., 2012). Landsat data are an obvious choice to obtain moderate spatial resolution $(30 m-120 m)$ SEB $E T_{a}$ estimates, given continued investment in the Landsat program (Roy et al., 2014) combined with access to processed and freely available historical archives of thermal, near infrared and visible imagery (Masek et al., 2006). Moving forwards, Landsat 8 (Feb. 2013 onwards, Roy et al., 2014) and Sentinel 3 (Feb. 2016 onwards, Donlon et al., 2012) data will provide the basis for current and future moderate spatial resolution $(10 m-90 m)$ cost-free 
SEB applications.

Over about 30 years of development (Carlson, 1986), different SEB algorithms now exist, such as the Surface Energy Balance System (SEBS) (Su, 2002), the Simplified Surface Energy Balance Index (S-SEBI) (Roerink et al., 2000), the Hybrid Dual-Source Scheme and Trapezoid Framework-Based Evapotranspiration Model (HTEM) (Yang and Shang, 2013), Mapping Evapotranspiration at High Resolution with Internalised Calibration (METRIC) (Allen et al., 2007), and others (Kustas and Norman, 1997; Long and Singh, 2012; Wang et al., 2014). Commonly, each algorithm employs a mechanism to constrain or reference sensible heat flux $\left(H, W m^{-2}\right)$ and latent heat flux $\left(\lambda E, W m^{-2}\right)$ to the energy available at the land surface $(A E)$; net radiation $\left(R_{N}, W m^{-2}\right)$ minus soil heat flux $\left(G, W m^{-2}\right)$. While the instantaneous sum of sensible and latent heat fluxes is not necessarily equal to $A E$ due to regional advection effects, its imbalance can be mitigated when $E T_{a}$ is quantified over daily time scales or longer (Allen et al., 2011a).

Within SEB models, the scaling or calibration of $H$ and $\lambda E$ is critical to ensure the surface energy balance can be satisfied (Kalma et al., 2008), for individual remotely sensed land units. Triangular (Gampe et al., 2016; Knipper et al., 2016; Petropoulos et al., 2009a) or trapezoidal (Long and Singh, 2012) techniques are distinct in their approach for the constraint and partitioning of $H$ and $\lambda E$ within SEB algorithms. They generally exploit the relationship between $T_{S}$ and a measure or index of vegetation $\left(T_{S^{-}} V I\right)$ (Carlson, 2007; Long et al., 2012; Price, 1990) to define boundaries or vertices associated with theoretical conditions of the surface energy balance. They have considerable utility and applicability over different environments and landscape scales, particularly those with limited ground reference data where there are often water management challenges (Gampe et al., 2016; Long et al., 2012).

Approaches vary for the choice of the vegetative axis, with most using the Normalised Difference Vegetation Index (NDVI) (Han et al., 2006; Sun, 2016; Yang and Shang, 2013), the fractional vegetation cover (Carlson, 2007), or the Leaf Area Index (LAI) (Han et al., 2006), while use of $T_{S}$ among existing ET triangle methods remains similar, apart from incorporating the difference to air temperature $\left(T_{A},{ }^{\circ} C\right)$ (Long and Singh, 2012). Automated detection or definition of triangle/trapezoidal boundaries and vertices is a crucial requirement for the fast and objective production of $E T_{a}$, particularly for deriving estimates over large areas (Elhaddad and Garcia, 2014) and dense time series.

$T_{S^{-}} V I$ triangle and trapezoidal models have performed well when compared to other 
forms of energy restraint (Lian and Huang, 2016; Long and Singh, 2013) and when validated against Large Aperture Scintillometers (LAS) (Tang et al., 2010) or eddy covariance flux towers (Long and Singh, 2012; Long et al., 2012). However, $T_{S^{-}} V I$ techniques are often limited to heterogeneous areas that exhibit different vegetation conditions, varying across a range of water availabilities (Long et al., 2012). Also, as the domain size and land unit resolution changes, $T_{S^{-}} V I$ boundaries or vertices may vary (Long et al., 2012) and questions remain as to whether a triangle or a trapezoidal theoretical structure better encompasses the complete range of $T_{S^{-}} V I$ values (Long et al., 2012), and at what areal scale triangle techniques can be successfully implemented (Long et al., 2012).

SEBS uniquely applies the Penman-Monteith combination equation (Monteith, 1965) to determine the residual $H\left(H_{w e t}, W m^{-2}\right)$ for conditions where $\lambda E$ reaches the upper potential rate $\left(\lambda E_{w e t}, W m^{-2}\right)(\mathrm{Su}, 2002)$, different to most SEB algorithms (Kalma et al., 2008). This removes a common evaporative energy control at the cold and wet limit common among many SEB algorithms, that $\lambda E_{\text {wet }}$ is equivalent to $A E$ (Bastiaanssen et al., 1998; Long and Singh, 2012; Yang and Shang, 2013). The METRIC algorithm also applies a similar evaporative control (Allen et al., 2007), however, it relies on the identification of representative land units relevant to $E T_{r}$ surface conditions (Allen et al., 2013). Comparatively, the determination of $H_{w e t} / \lambda E_{\text {wet }}$ by SEBS is spatially explicit and is not restricted by the need to identify specific land units. This makes SEBS more applicable to the estimation of $E T_{a}$ over non-agricultural land types, where the composition of plant and tree species can be heterogeneous and is often largely unknown.

McCabe and Wood (2006) reported consistent flux estimates between different satellite platforms and at different spatial scales, indicating SEBS has good utility to create multiscale high spatial and temporal resolution $E T_{a}$ datasets, useful for hydrological accounting. When SEBS has been compared to other SEB algorithms it has been show to perform well. Tang et al. (2011) found comparable performance to the Two-Source Energy Balance (TSEB) model and improved performance to a $T_{S^{-}} V I$ triangle technique over wheat and corn agricultural land types. Yang and Shang (2013) obtained a root mean squared error (RMSE) for SEBS slightly larger than that for HTEM in wheat and corn, and Webster et al. (2016) showed SEBS had lower RMSE compared to S-SEBI and HTEM in forested and sub-alpine grassland land types. Furthermore, the current implementation of SEBS contains some structural limitations that if addressed may further improve its performance and applicability across different land types. 
SEBS's constraint of $H$ is different from other SEB algorithms; the initial unbounded estimates of $H$ and $H_{\text {wet }}$ are used directly to calculate evaporative fraction $(\Lambda)$ (Su, 2002). While $H_{\text {wet }}$ can not exceed $A E$, there is no current control to enforce $H$ to be greater than $H_{\text {wet }}$ or less than $A E(\mathrm{Su}, 2002)$. This makes SEBS vulnerable to errors and bias within input variables related to the determination of $H$ and $H_{\text {wet }}$ (Liaqat and Choi, 2015). These error sources include: the interpolative uncertainty in the calculation of $T_{A}$, wind speed $\left(U_{x}, m s^{-1}\right)$, vapour pressure $\left(P_{v a p}, k P a\right)$, and solar exposure $\left(\delta, M J d a y^{-1}\right)$ (Elhag, 2016; Webster et al., 2016); errors and bias in $T_{S}$ associated with the atmospheric correction for atmospheric transmissivity $(\tau)$, upwelling path radiance $\left(R_{\text {path }}\right)$ and downwelling sky radiance $\left(R_{\text {sky }}\right)$ (Allen et al., 2011a); landscape heterogeneity (Gibson et al., 2011; Rwasoka et al., 2011); and the uncertainty in vegetation fraction and $\sigma_{s}$ given the absence of accurate land type classifications (Gibson et al., 2011). For example, SEBS was significantly more sensitive to errors in $T_{S}$ and leaf area index ( $\left.L A I\right)$ inputs compared to TSEB (Tang et al., 2011). Furthermore, Timmermans et al. (2013) used the Soil Canopy Observation, Photochemistry and Energy fluxes (SCOPE) model to evaluate and validate SEBS by simulation of remote sensing input variables. They identified large uncertainties in SEBS $G$ and $H$ driven primarily by the original parametrisation for the roughness height for heat transfer $\left(Z_{O H}, m\right)(\mathrm{Su}$, 2002), which was not suitable for tall canopies such as maize (Timmermans et al., 2013). After improving $Z_{O H}$ using $L A I$ to account for tall vegetation, $H$ was still underestimated and $\lambda E$ overestimated (Timmermans et al., 2013). Also acknowledging the limitation in $Z_{O H}$, Gokmen et al. (2012) utilised microwave soil moisture measurements to account for increased water stress for $Z_{O H}$ in the semi-arid Konya basin Turkey, improving estimations of SEBS flux components. Unfortunately, availability of supplementary microwave soil moisture measurements is often scarce in remote or heterogeneous environments (Daly, 2006).

The overall goal of this research was straightforward; to evaluate the effectiveness of adding a two dimensional $(E V I-H)$ energy restraint process into the SEBS algorithm (SEBS-ER) to improve its operation, accuracy and temporal stability. Given the development task and the three performance aspects for algorithm improvement, we separated our research into four specific aims: a) to effectively integrate an energy restraint component into the original SEBS algorithm; b) to evaluate how this improved resilience to errors and bias in meteorological and remotely sensed inputs; c) to identify how this improved SEBS algorithm accuracy with respect to independent validation data; and d) to show that SEBS-ER improved the temporal stability of SEBS estimates over extended time frames and various 


\section{Background Theory}

Below, we outline the execution of the existing SEBS process from Su (2002) specific to the determination of $H$ and $\lambda E$. The SEBS $H$ and $\lambda E$ partitioning process starts with the definition of aerodynamic resistance $\left(R_{A H}, s m^{-1}\right)(1)$. Su (2002) uses Monin-Obukhov (MO) stability correction functions for heat $\left(\Psi_{h}\right)$ and momentum $\left(\Psi_{m}\right)$ (Brutsaert, 1999) to define a single source estimate of $R_{A H}$ between the ground and the Atmospheric Surface Layer (ASL) (1):

$$
R_{A H}=\frac{\left[\ln \frac{Z_{h}-D_{0}}{Z_{0 H}}-\Psi_{h} \frac{Z_{h}-D_{0}}{L}+\Psi_{h} \frac{Z_{0 H}}{L}\right]}{U_{*} k}
$$

where $k$ is von Karmen's constant (0.41), $Z_{O H}$ is the roughness height for heat transport $(m)$ referenced to the height of the air temperature observation $\left(Z_{h}, m\right)$, and $D_{o}$ is the zero plane displacement height $(m) . U_{*}$ is the friction velocity to momentum transport $(2)$ :

$$
U_{*}=\frac{U_{x} k}{\left[\ln \frac{Z_{m}-D_{0}}{Z_{0 M}}-\Psi_{m} \frac{Z_{m}-D_{0}}{L}+\Psi_{m} \frac{Z_{0 M}}{L}\right]}
$$

within the ASL where $Z_{m}$ is the height $(m)$ of the wind speed observation $\left(U_{x}, m s^{-1}\right), Z_{O M}$ is the roughness height for momentum transport $(m)$, and $L$ is the MO length $(3, m)$.

$$
L=-\frac{\rho C_{p} U_{*}^{3} T_{V}}{k g H}
$$

Where $\rho$ is the density of the air $\left(\mathrm{kg} \mathrm{m}^{-3}\right), C_{p}$ is the specific heat constant for air (1012 $\left.J \mathrm{~kg}^{-1} \mathrm{~K}^{-1}\right), \mathrm{g}$ is the gravitational constant $\left(9.81 \mathrm{~m} \mathrm{~s}^{-2}\right)$, and $T_{V}$ is the virtual temperature of the air $\left({ }^{\circ} C\right)$. With $R_{A H}$ estimated, SEBS derives $H(4)$ :

$$
H=\frac{\rho C_{p}\left(T_{S}-T_{A}\right)}{R_{A H}}
$$

and uses it to progressively adjust $R_{A H}$ through $L(3)$ via $\Psi_{m}$ and $\Psi_{h}$ until a stable solution is reached for $H$.

SEBS does not require that $\lambda E$ is equivalent to $A E$ under conditions of maximum evaporation $\left(\lambda E_{\text {wet }}, W m^{-2}\right)(\mathrm{Su}, 2002)$, rather it assumes $H_{\text {wet }}$ and $\lambda E_{\text {wet }}$ sum to $A E(5)$ :

$$
H_{\text {wet }}=R_{N}-G-\lambda E_{\text {wet }} .
$$

$\mathrm{Su}(2002)$ estimates $H_{\text {wet }}$ from an adaption of the Penman Monteith combination equation (Monteith, 1965) (6):

$$
H_{w e t}=\left(\left(R_{N}-G\right)-\frac{\rho C_{p}}{R_{E W}} \cdot \frac{P_{s a t}-P_{v a p}}{\gamma}\right) /\left(1+\frac{\Delta}{\gamma}\right)
$$


where $P_{\text {sat }}$ is saturated vapour pressure $(k P a), \gamma$ is the psychometric constant $\left(0.073 k P a^{\circ} C^{-1}\right)$,

$\Delta$ is the slope of the saturation pressure curve and $R_{E W}$ is the external resistance to heat transport $\left(7, s m^{-1}\right)$ at $\lambda E_{w e t}$ :

$$
R_{E W}=\frac{1}{k U_{*}}\left[\ln \left(\frac{Z_{h}-D_{o}}{Z_{0 H}}\right)-\Psi_{h}\left(\frac{Z_{h}-D_{o}}{L_{w e t}}\right)+\Psi_{h}\left(\frac{Z_{0 H}}{L_{w e t}}\right)\right] .
$$

$L_{\text {wet }}$ is the MO length at $\lambda E_{\text {wet }}(8, m)$ :

$$
L_{w e t}=-\frac{\rho U_{*}^{3}}{k g 0.61\left(R_{N}-G\right) / \lambda}
$$

and $\lambda$ is the latent heat of vaporisation of water $\left(2.26, \mathrm{MJ} \mathrm{kg}^{-1}\right)$.

Considering $H_{w e t}$, Su (2002) defines the relative evaporative fraction $\left(\Lambda_{r}\right)$ as $(9)$ :

$$
\Lambda_{r}=1-\frac{H-H_{w e t}}{R_{N}-G-H_{w e t}}
$$

to derive the evaporative fraction $(\Lambda)(10)$ :

$$
\Lambda=\Lambda_{r} \frac{\left(R_{N}-G-H_{w e t}\right)}{R_{N}-G}
$$

to determine $\lambda E$ from $A E(11)$

$$
\lambda E=\Lambda_{r}\left(R_{N}-G-H_{w e t}\right)=\Lambda\left(R_{N}-G\right) .
$$

\section{Site Details and Data}

\subsection{Study Sites}

Our research addressed the four objectives across two study areas represented by two Landsat image tiles (path 90 row 84 and path 91 row 85) (Fig. 1). The Canberra study area $\left(37,648 \mathrm{~km}^{2}\right)$, represented by Landsat image tile path 91, row 85 in south-east Australia, featured agricultural and grazing land types in the north-west corner through to tall forested mixed eucalyptus forests $(>40 \mathrm{~m}$ ) and alpine grasslands (Keith, 2004) in the central and south-east extents. Modelled vegetation height (Scarth, 2014) varied across these land use types from $0.1 \mathrm{~m}$ in the agricultural and grazing areas through to $28 \mathrm{~m}$ in the forested regions (Fig. 1). Topography varied substantially around the Great Dividing Range, ranging from 2,228 $m$ in the alpine areas to $41 m$ in the western agricultural areas (Fig. 1). Mean annual precipitation ranged from $2180 \mathrm{~mm}$ in the alpine areas along the Great Dividing Range to $520 \mathrm{~mm}$ in the far north-west corner of the study area (Fig. 1).

The Sydney study area $\left(38,129 \mathrm{~km}^{2}\right)$, represented by Landsat image tile path 90 , row 84 in south-east Australia, within one river basin, incorporated 16 catchment areas with 


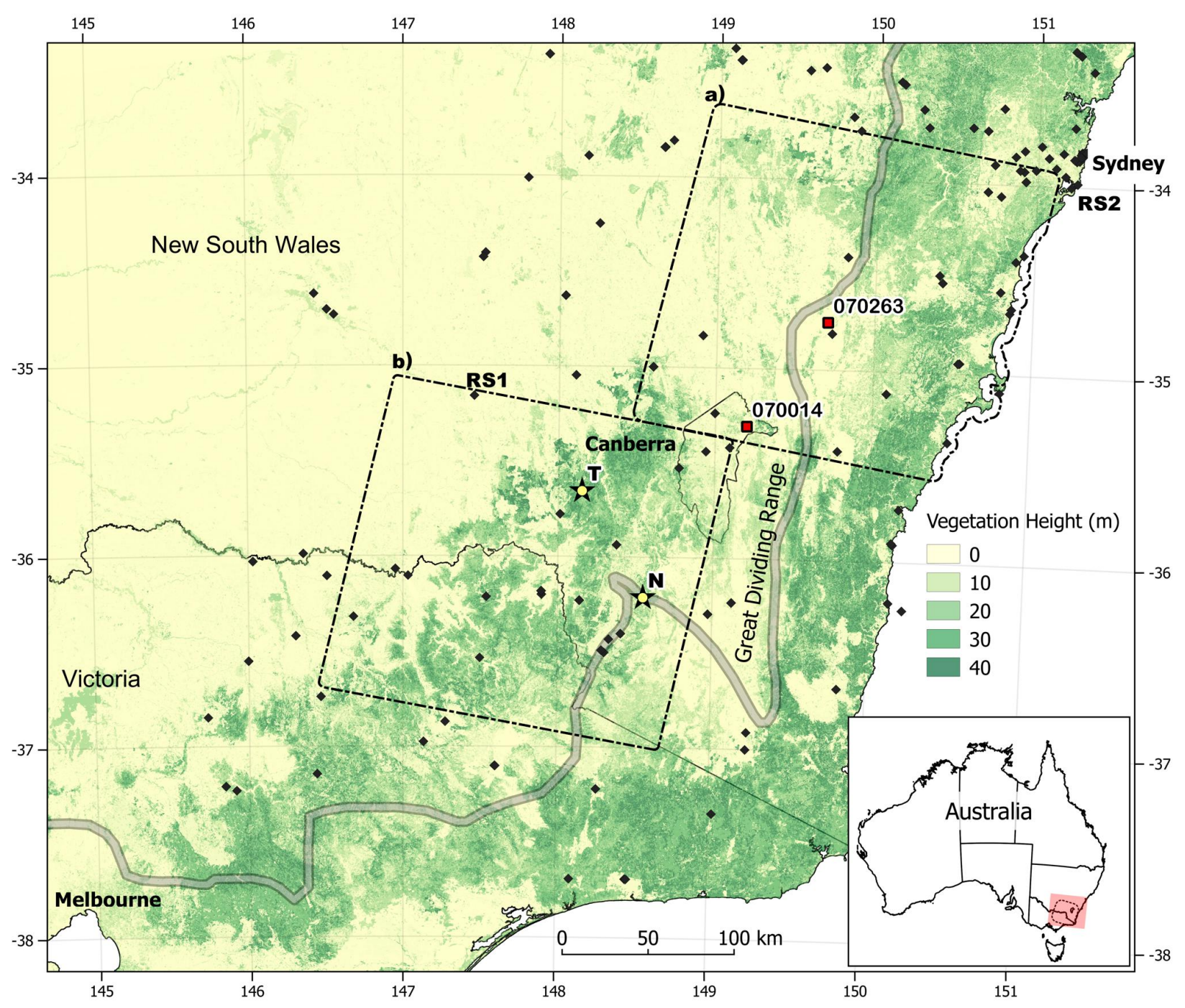

Figure 1: Two study areas in south-east Australia: a) the Sydney study area (Landsat tile (path 90, row 84)) contained two long term pan evaporation stations (squares with station IDs); and b) the Canberra study area (Landsat tile (path 91, row 85)), with the Tumbarumba (star T) and Nimmo High Plains (star $\mathrm{N}$ ) eddy covariance flux towers. Dark grey diamonds were the meteorological ground stations used to source $T_{A}, U_{x}, P_{v a p}$, and $P_{a i r}$ meteorological inputs for SEBS and SEBS-ER. The RS1 annotation indicates the location of the Wagga Wagga radiosonde station and the RS2 annotation indicates the location of the Sydney International airport radiosonde station. Coloured Shading showed relative height of the vegetation across south east Australia (Scarth, 2014). The WGS 84 coordinate grid was overlaid on top of the map UTM 55N projection.

diverse topography and land types (Fig. 1). The Great Dividing Range ran through the centre (North to South) of the Sydney study area, partitioning coastal and inland meteorological processes (Fig. 1). We analysed data over about 10 years (1 Dec 1999 - 22 Mar 2010), including two large wildfires (2001 and 2007), many hazard reduction burns, heavy precipitation events and dry periods, creating a heterogeneous landscape with a dynamic range of $E T_{a}$ values. Elevation extended from sea level through to $1593 \mathrm{~m}$, with a large 

plateau between 600-800 $m$ to the east of the Great Dividing Range (Fig. 1). Modelled vegetation height (Scarth, 2014) ranged from $0.1 \mathrm{~m}$ in agricultural and grazing areas through to $28 \mathrm{~m}$ in the south-west corner of the study area (Fig. 1). Mean annual precipitation featured a distinct band between $600-900 \mathrm{~mm}$ extending to $1847 \mathrm{~mm}$ halfway along the eastern coastal boundary down to $617 \mathrm{~mm}$ within the northern limits of Australia's Capital Territory (ACT).

\subsection{Input Data}

Landsat 5 Thematic Mapper (TM) and Landsat 7 Enhanced Thematic Mapper (ETM+) surface reflectance and thermal data were used as the foundation for our analyses. Nine Landsat 5 TM acquisitions were obtained for the Canberra study area, all featuring less than $30 \%$ cloud contamination (Fig. 2a). Fifty-two acquisitions were obtained for the
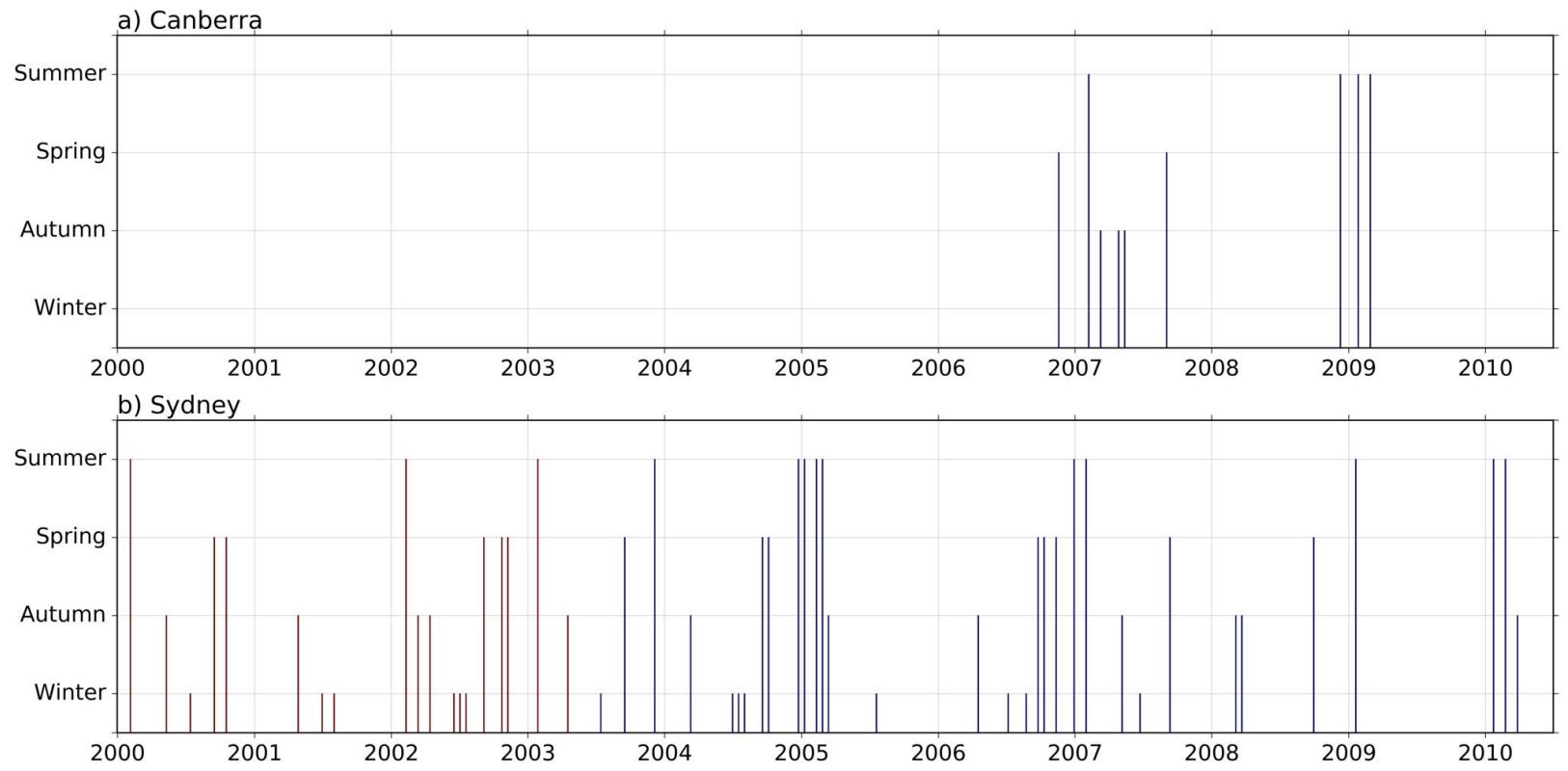

Figure 2: a) Nine Landsat acquisition dates for the Canberra study area (Fig. 1) were used to test the sensitivity, resilience and accuracy of the SEBS and SEBS-ER surface energy balance algorithms. All nine Landsat acquisitions were from the Landsat 5 Thematic Mapper (TM) (blue). b) Fifty-two Landsat acquisition dates for the Sydney study area (Fig. 1) were used to test the temporal stability of the SEBS and SEBS-ER surface energy balance algorithms. The Landsat data (1 Dec 1999 - 16 Apr 2003) were acquired by the Landsat 7 ETM+ (red) while Landsat data from 13 Jul 2003 onwards were acquired by the Landsat 5 TM (blue).Precise acquisition dates ca be found within the atmospheric correction tables located in Appendix A.

Sydney study area: 20 Landsat 7 ETM+ acquisitions (1 Dec 1999 - 16 Apr 2003) and 32 Landsat 5 acquisitions (13 Jul 2003 - 26 Mar 2010) (Fig. 2b). Given the limited number of Landsat 5 scenes in the period prior to its shutdown and the start of Landsat 8 operational 
data (Feb 2013), no Landsat 8 data were used within the analysis. Details of the source and preprocessing of the multispectral, meteorological, topographic, and vegetation height data are outlined in Appendix A.

Within the Canberra study area, data from two eddy covariance flux towers were obtained from OzFlux (Leuning, 2002; Simpson, 2012) (Fig. 1), over the range of acquisition dates (Fig. 2a). The first tower was at Tumbarumba (Fig. 1), a $70 \mathrm{~m}$ high tower within a $40 \mathrm{~m}$ high wet sclerophyll forest. The second tower was on the Nimmo High Plains of the Monaro region (Fig. 1), in seasonally grazed sub-alpine grassland with a tower height of $2.5 \mathrm{~m}$.

\section{Methods}

\subsection{Implementation of the SEBS Energy Restraint}

Daily and synoptic meteorological data were collated for each Landsat acquisition date, for each study area (Fig. 1). $T_{M}$ and $T_{X}$ data were temporally interpolated to $T_{A}$ at the time of the Landsat acquisition using the TM method (Cesaraccio et al., 2001), while $U_{x}, P_{\text {air }}$ and $P_{\text {vap }}$ were linearly interpolated from previous and subsequent observations. Before spatial interpolation using Inverse Distance Weighting (IDW), the near surface elevation dependence (NSED) of $T_{A}, U_{x}, P_{a i r}, P_{v a p}$ and $\delta$ meteorological inputs were determined using radiosonde and monthly averages, see Webster et al. (2016). For the Canberra area, radiosonde data were sourced from the Wagga Wagga meteorological station (Fig. 1), and for the Sydney area, radiosondes were averaged between Wagga Wagga and Sydney International Airport meteorological stations (Fig. 1).

From the interpolated meteorological and remotely sensed data, common surface energy balance (SEB) variables were derived, see Webster et al. (2016). This included the calculation of Leaf Area Index $(L A I)$, Atmospheric Emissivity $\left(\epsilon_{a}\right)$, Surface Emissivity $\left(\epsilon_{o}\right)$, Surface Albedo $\left(\sigma_{s}\right)$, Air Density $(\rho)$, Net Radiation $\left(R_{N}\right)$, Soil Heat Flux $(G)$, and Roughness Length for Momentum $\left(Z_{O M}\right)$. Timmermans et al. (2013) reported that SEBS $\lambda E$ was overestimated in tall canopies $(>1 \mathrm{~m})$ when the roughness length for heat transport $\left(Z_{O H}\right)$ was derived using the methods of $\mathrm{Su}$ (2002). So, we adopted a simplified definition of $Z_{O H}$ (12), more applicable to heterogeneous landscapes (Garratt and Hicks, 1973) exhibited by the vegetation type and canopy height throughout our study areas (Fig. 1) (Keith, 2004).

$$
Z_{O H}=\frac{Z_{O M}}{7}
$$

Landsat 5 and 7 thermal data were sharpened using the TsHARP technique for Landsat imagery with a linear relationship to fractional vegetation cover. This configuration was 


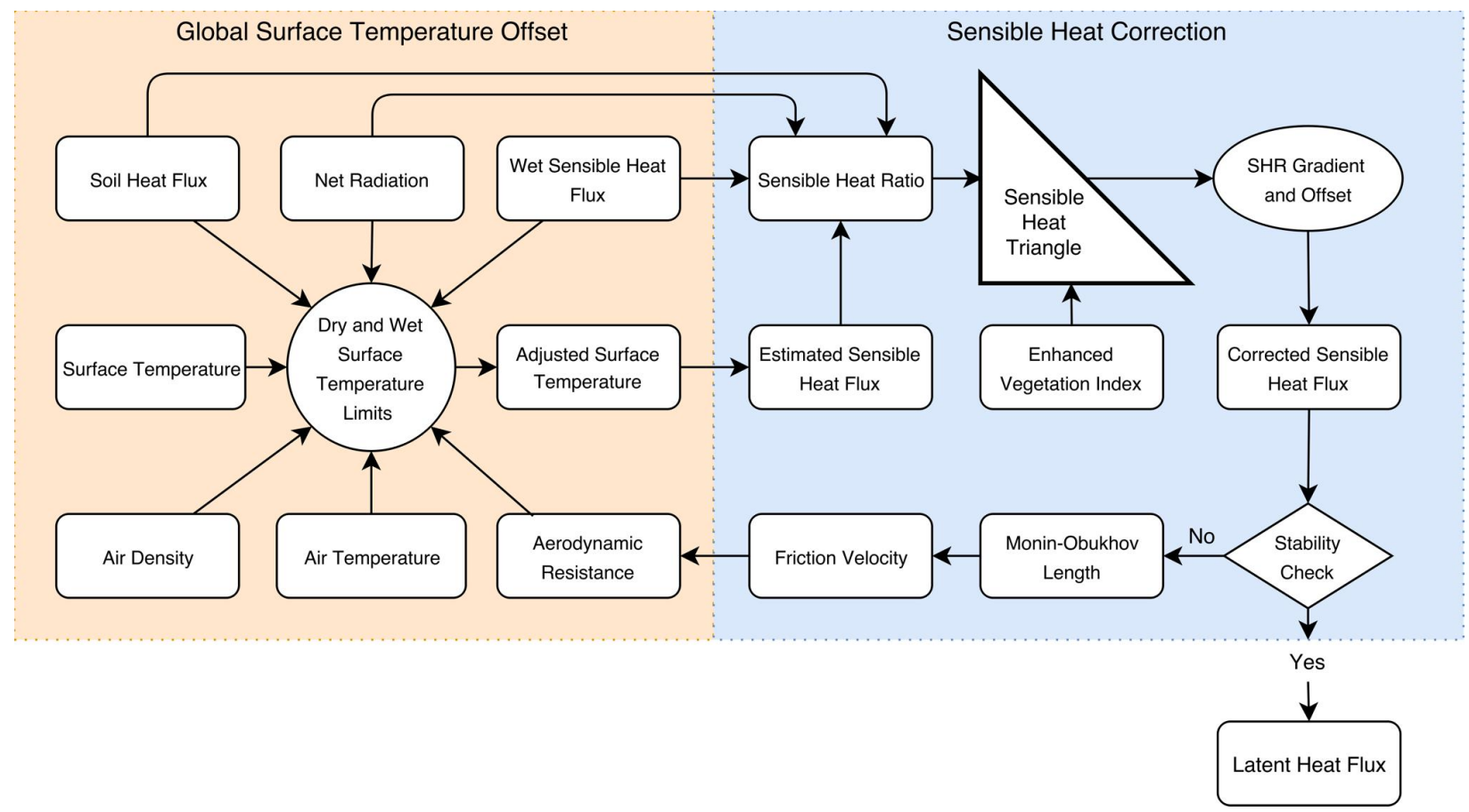
B of Webster et al. (2016). Reduced $(60 \mathrm{~m}$ ) aggregated pixel sizes were used to reflect the increased resolution of Landsat 7 thermal data in the Sydney study area.

Figure 3: A flowchart depicting the two stage energy restraint incorporated into the Surface Energy Balance System. The first stage (orange shaded area) quantifies a global offset for surface temperature, while the second stage (blue shaded area) uses a domain-based image search routine to identify the limits of the Sensible Heat Ratio $(S H R)$ to make a gradient and offset correction to sensible heat flux $(H)$. The routine continues until the aerodynamic resistance and the gradient and offset correction parameters stabilise.

selected given its relative performance to other sharpening approaches outlined by (Agam et al., 2007). The processing steps used for thermal sharpening are provided in Appendix 
estimate (Allen et al., 2011b), the interpolative errors in the $T_{A}$ and $U_{x}$ estimates (Webster et al., 2016), and the limitations in the simplified representations for the roughness for heat and momentum transport within the SEBS algorithm (Timmermans et al., 2013). The first stage added a scene-wide offset to $T_{S}\left(T_{S a d j}\right)$ to ensure the virtual difference between $T_{S}$ and $T_{A}$ was considerate of both the lower limit of $H\left(H_{w e t}\right)$, the upper limit of $H\left(R_{N^{-}} G\right)$, and mitigated any excessive underestimations or overestimations in $R_{A H}$. While this first stage was not designed to vastly improve the accuracy of the SEBS algorithm alone, it was critical to the successful resolution for the second stage of analysis, by ensuring that, on average, $T_{A}$ did not exceed $T_{S}$. To determine the global surface temperature offset (Fig. 3), we used $R_{A H}$ and $\rho$ to estimate $T_{S}$ at the wet limit $\left(T_{\text {Swet }}\right)(13)$ :

$$
T_{\text {Swet }}=\frac{H_{w e t} R_{A H}}{\rho C_{p}}+T_{A}
$$

and $T_{S}$ at the dry limit $\left(T_{S d r y}\right)(14)$ :

$$
T_{S d r y}=\frac{\left(R_{N}-G\right) R_{A H}}{\rho C_{p}}+T_{A} .
$$

Using $T_{\text {Swet }}$ and $T_{\text {Sdry }}, T_{S}$ was then adjusted $\left(T_{\text {Sadj }}\right)$, by a global offset, to move the $50^{\text {th }}$ percentile of unmasked $30 \times 30 \mathrm{~m}$ land units halfway between $T_{\text {Swet }}$ and $T_{\text {Sdry }}(15)$ :

$$
T_{\text {Sadj }}=T_{S}+50^{t h} \text { percentile of }\left(\frac{T_{\text {Sdry }}+T_{\text {Swet }}}{2}-T_{S}\right) .
$$

Given $T_{\text {Sadj }}$, we altered Eq. 4 to initially estimate $H\left(H_{E}\right)(16)$ :

$$
H_{E}=\frac{\rho C_{p}\left(T_{\text {Sadj }}-T_{A}\right)}{R_{A H}}
$$

and used it to define the sensible heat ratio (SHR) (17) to relate the difference between $H_{E}$ and $H_{w e t}$ to the range of available evaporative energy $\left(R_{N}-G-H_{w e t}\right)$.

$$
S H R=\frac{H_{E}-H_{w e t}}{R_{N}-G-H_{w e t}}
$$

In the second stage of the energy restraint routine (Fig. 3), we collated the estimate of SHR against corresponding values of the enhanced vegetation index (EVI) (Masek et al., 2006). The resulting two-dimensional (2D) density distribution produced the sensible heat triangle (SHT) (Fig. 3 and Fig. 4), representative of conditions within the masked Landsat tile. EVI was used as an indicator of fractional vegetation cover as it provided improved delineation at the top of the sensible heat triangle, unlike $N D V I$ which is more prone to saturation (Huete et al., 2002). The image processing procedure for determining the 


\section{b)}

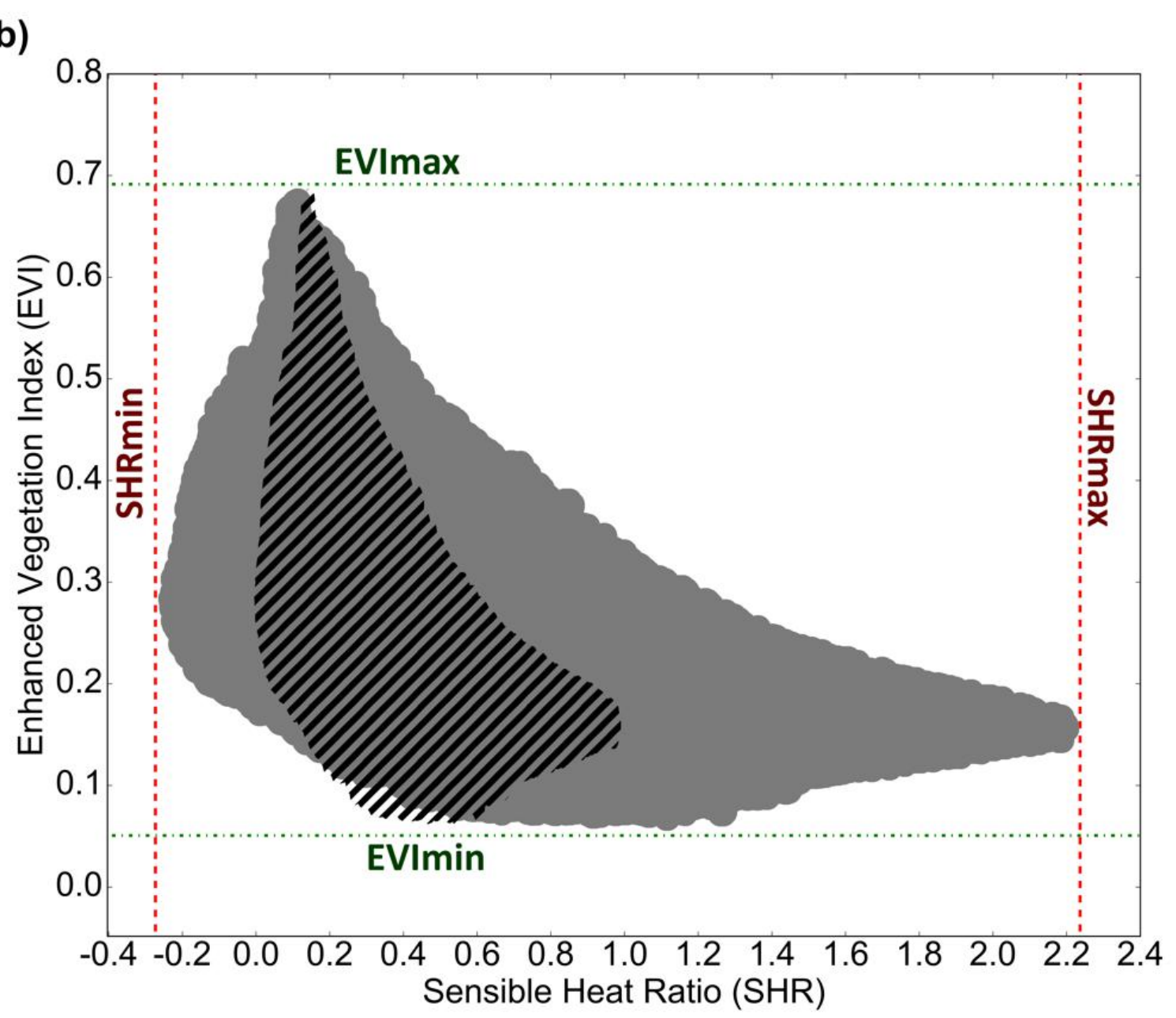
(Fig. 4). Correspondingly, the upper $S H R$ boundary $\left(S H R_{M A X}\right)$ represented the hot and dry landscape limit of energy flux processes, where $\lambda E$ equals zero and $H$ equals $A E$ (Fig. $4)$.

Figure 4: The constraint and adjustment of the SEBS-ER Sensible Heat Triangle $(S H T)$, defined by $S H R_{M A X}$ and $S H R_{M I N}$ values and a gradient $\left(A_{E R}\right)$ and intercept $\left(B_{E R}\right)$ applied to adjust the input $S H T$ distribution (shaded grey) to a new $S H T$ with an $S H R$ ranged between 0 and 1 (dark striped).

boundaries of the $S H T$ are outlined in Appendix B. The lower $S H R$ boundary $\left(S H R_{M I N}\right)$ represented the cool and wet landscape limit of energy flux processes, represented by Eq. 5

The automated image based estimates of $S H R_{M I N}$ and $S H R_{M A X}$ (Fig. 4) were then used to adjust $H_{E}$ via linear gradient $\left(A_{E R}\right)$ and intercept $\left(B_{E R}\right)$ coefficients (18) to obtain a corrected sensible heat flux $\left(H_{C}\right)$, appropriately constrained with respect to $A E$ (Fig. 4).

$$
\frac{H_{C}-H_{w e t}}{R_{N}-G-H_{w e t}}=A_{E R}\left(\frac{H_{E}-H_{w e t}}{R_{N}-G-H_{w e t}}\right)+B_{E R}
$$

To determine $A_{E R}$ and $B_{E R}$ and constrain the range of $S H R$ between 0 and 1 (Fig. 4), the 
hot and dry limit, $S H R_{M A X}$, was used (19):

$$
\frac{H_{E}-H_{w e t}}{R_{N}-G-H_{w e t}}=S H R_{M A X} \rightarrow \frac{H_{C}-H_{w e t}}{R_{N}-G-H_{w e t}}=1.0
$$

with the max evaporative limit, $S H R_{M I N}(20)$ :

$$
\frac{H_{E}-H_{w e t}}{R_{N}-G-H_{w e t}}=S H R_{M I N} \rightarrow \frac{H_{C}-H_{w e t}}{R_{N}-G-H_{w e t}}=0.0
$$

to solve a solution for $A_{E R}(21)$ :

$$
A_{E R}=\frac{1.0}{S H R_{M A X}-S H R_{M I N}}
$$

and $B_{E R}(22)$ :

$$
B_{E R}=-\frac{S H R_{M I N}}{S H R_{M A X}-S H R_{M I N}} .
$$

$A_{E R}$ and $B_{E R}$ were then used with Eq. 18 to derive $H_{C}$ explicitly (23):

$$
H_{C}=A_{E R}\left(H_{E}-H_{w e t}\right)+B_{E R}\left(R_{N}-G-H_{w e t}\right)+H_{w e t} .
$$

This geospatial processing and image analysis sequence $(3,2,1,13,14,15,16,8,7,6$, 18, 21, 22 and 23) was repeated with MO corrections until consecutive estimates of $A_{E R}$ and $B_{E R}$ differed by less than $1.5 \%$. At this point $\lambda E$ was solved as the residual of the energy balance (24):

$$
\lambda E=R_{N}-G-H_{C} .
$$

\subsection{Sensitivity of SEBS and SEBS-ER to Input Error}

The SEBS and SEBS-ER sensitivity analysis were conducted only in the Canberra study area, as impacts from land use change and disturbance events within the Sydney area would have likely complicated the results. We tested the sensitivity against six input variables, used in the calculation of SEB and SEBS-ER $H$ and $\lambda E$. The inputs consisted of two key remotely sensed variables $\left(T_{S}\right.$ and $Z_{o m}$ ) (Petropoulos et al., 2009b) and four key meteorological variables $\left(T_{A}, U_{x}, P_{\text {vap }}\right.$, and $\delta$ ) (Elhag, 2016; Webster et al., 2016). For the analysis, $T_{S}$ and $T_{A} 30 \times 30 \mathrm{~m}$ land units were randomly perturbed by $2{ }^{\circ} \mathrm{C}$ (Yang and Shang, 2013), while $U_{x}, P_{\text {vap }}$, and $\delta$ land units were randomly perturbed by $20 \%$ (Yang and Shang, 2013). Following the analysis by Timmermans et al. (2013), $Z_{\text {om }}$ land units were randomly perturbed by $50 \%$. For each acquisition date, separate estimations of $\lambda E$ were obtained from SEBS and SEBS-ER for the variation of each sensitivity input, while the remaining five variables were left unperturbed. The sensitivity of SEBS and SEBS-ER $\lambda E$ were then derived for each 
input variable $\left(\Delta \lambda E_{V A R}\right)$ (25) (Yang and Shang, 2013), collated across the four acquisition dates:

$$
\Delta \lambda E_{V A R}=\frac{\lambda E_{\text {pert }}-\lambda E_{\text {init }}}{100\left(V A R_{\text {pert }}-V A R_{\text {init }}\right) / V A R_{\text {init }}},
$$

where $\lambda E_{\text {pert }}$ was the $\lambda E$ from the perturbed input $\left(V A R_{\text {pert }}\right)$ and $\lambda E_{\text {init }}$ was the $\lambda E$ from the unperturbed input $\left(V A R_{\text {init }}\right)$. Linear regressions of the resultant distributions were then used to compare the relative sensitivity of SEBS and SEBS-ER to variation in each of the six input variables. Additionally, average spatially explicit grids of the absolute sensitivity of $\lambda E$ per percent change in each input variable were plotted for SEBS and SEBS-ER.

\subsection{Validation and Performance of SEBS and SEBS-ER}

Validation was conducted within the Canberra study area across the nine acquisition dates (Fig. 2a). The two flux towers, in contrasting land types, were used to compare the relative accuracy of the existing SEBS algorithm to the new SEBS-ER technique. All input data were consistent between the two algorithms, producing common estimates of $Z_{O M}$, $Z_{O H}, \rho, \sigma_{s}, R_{N}$, and $G$. $\lambda E$ was used rather than $E T_{a}$, as the basis for comparison to the two flux towers, to remove the uncertainty and errors associated with the temporal scaling of instantaneous fluxes to daily $E T_{a}$ estimates (Van Niel et al., 2012, 2011). SEBS and SEBSER $\lambda E$ estimates were compared to HTEM and S-SEBI data obtained from Webster et al. (2016). At the $70 \mathrm{~m}$ high Tumbarumba flux tower (Fig. 1), a $750 \mathrm{~m}$ radial footprint (see van Gorsel et al., 2013) was used to sample $\lambda E$ from S-SEBI, HTEM, SEBS, and SEBS-ER outputs on each of the nine acquisition dates in the Canberra study area (Fig. 2a). At the $2.5 \mathrm{~m}$ high Nimmo High Plains flux tower (Fig. 1), a $30 \mathrm{~m}$ radial footprint was used for sampling given the comparative height between the two towers and the lower canopy height (Scarth, 2014). This tower only recorded $\lambda E$ data on the 9 Mar 2007, 12 May 2007, and 1 Sep 2007 acquisition dates. For each flux tower and acquisition date compared, the mean and plus or minus two standard deviations from the collection of $30 \times 30 \mathrm{~m}$ land unit samples were plotted against flux tower $\lambda E$ for S-SEBI, HTEM, SEBS, and SEBS-ER.

\subsection{Temporal Stability of SEBS and SEBS-ER}

Fifty-two acquisitions of Landsat 5 and 7 data from the Sydney study area were combined with meteorological and land use data to produce daytime estimates of $E T_{a}$ for both SEBS and SEBS-ER. Given the outcomes from Van Niel et al. (2011) and Van Niel et al. (2012), the temporal scaling of $\lambda E$, from Eq. 24, was restricted to a daytime only estimate of $E T_{a}$ 
for SEBS and SEBS-ER, using the daily/daytime quantification of solar exposure $(\delta)$ and the assumption that $\Lambda$ was constant over daytime hours (26):

$$
E T_{a}=\Lambda \frac{\delta\left(1-\sigma_{s}\right)}{\lambda \rho_{w}},
$$

where $\rho_{w}$ was the density of water $\left(1.000 \mathrm{~kg} \mathrm{~m}^{-3}\right)$.

We compared the 52 SEBS and SEBS-ER daily ET maps in the Sydney study area (Fig. 1) against a daily $250 \mathrm{~m} E T_{a}$ dataset in the absence of field based $E T_{a}$ measures or other forms of validation data. While the comparison between two $E T_{a}$ algorithms was not ideal in terms of assessing absolute accuracy, such as that from a localised flux tower, it did enable a spatially explicit scene-wide comparison to be drawn among all land units across the landscape. The $250 \mathrm{~m}$ daily $E T_{a}$ dataset was derived from a realisation of the PT-JPL algorithm (Fisher et al., 2008) executed using: the MOD13Q1 NDVI product (USGS, 2009); the SRTM v3 1 arc second elevation product (Gallant et al., 2011); and BOM $T_{M}, T_{X}, P_{v a p}$, $P_{\text {sat }}$, and $\delta$ observation data, the same as that used for SEBS and SEBS-ER ET estimates. To allow direct comparison, $30 \mathrm{~m}$ SEBS and SEBS-ER $E T_{a}$ data were first resampled to 250 $m$ by aggregation.

The PT-JPL algorithm was adapted from the data model provided by Fisher et al. (2008) (josh.yosh.org/datamodels.htm) for use with spatial grids of NDVI and meteorological data. PT-JPL is a process driven model (Fisher et al., 2008), well suited to derive temporally continuous and accurate estimations of $E T_{a}$ (Chen et al., 2014), using coarse scale data such as MODIS (Yao et al., 2013). It relies on comparatively little input data and does not require thermal infrared data, unlike SEBS or SEBS-ER, making it more temporally stable than SEBS and better suited to continuous daily realisations of $E T_{a}$ data (Yao et al., 2013). Given this, the validation using PT-JPL $E T_{a}$ data was directed and limited towards assessing the temporal stability of SEBS-ER, compared to SEBS within the Sydney study area (Fig 1).

To achieve a comprehensive comparison between SEBS/SEBS-ER and PT-JPL data, we undertook three aspects of analysis. First, we determined the spatially explicit $E T_{a}$ RMSE between SEBS and SEBS-ER to PT-JPL data across all 52 acquisition dates, then we produced density distribution plots comparing $E T_{a}$ between SEBS and SEBS-ER to PTJPL, and finally we subset the mean absolute error between SEBS and SEBS-ER to PT-JPL by season. The final form of validation data we used were pan evaporation records for two BOM stations within the Sydney study area (Fig. 1). Pan evaporation records can not be used as a direct form of validation for $E T_{a}$ data (McMahon et al., 2013) but they do 
Table 1: Summary of the SEBS-ER calibration parameters for the final Monin Obukhov (MO) iteration used for all nine acquisition dates in the Canberra study area (Fig. 2a). The $T_{S}$ offset was the global shift that centred the distribution between the theoretical wet and dry $T_{S}$ limits, while the $S H R$ (Sensible Heat Ratio) gradient and intercept coefficients constrained the range of $S H R$, between the limits of available evaporative energy, ranged between zero and one. The mean and standard deviation (SD) were calculated from all Canberra acquisition dates (Fig. 2a).

\begin{tabular}{llll}
\hline Date & $T_{S}$ offset $(K)$ & SHR Gradient & SHR Intercept \\
\hline 17 Nov 2006 & 2.48 & 0.340 & 0.224 \\
5 Feb 2007 & -4.51 & 0.142 & 0.328 \\
9 Mar 2007 & 3.98 & 0.352 & 0.217 \\
26 Apr 2007 & 3.78 & 0.201 & 0.221 \\
12 May 2007 & 3.61 & 0.119 & 0.298 \\
1 Sep 2007 & 4.64 & 0.109 & 0.091 \\
8 Dec 2008 & 0.64 & 0.181 & 0.227 \\
25 Jan 2009 & 7.89 & 0.290 & 0.072 \\
26 Feb 2009 & 10.77 & 0.448 & 0.134 \\
\hline Mean (SD) & $3.70(4.04)$ & $0.242(0.113)$ & $0.201(0.082)$ \\
\hline
\end{tabular}



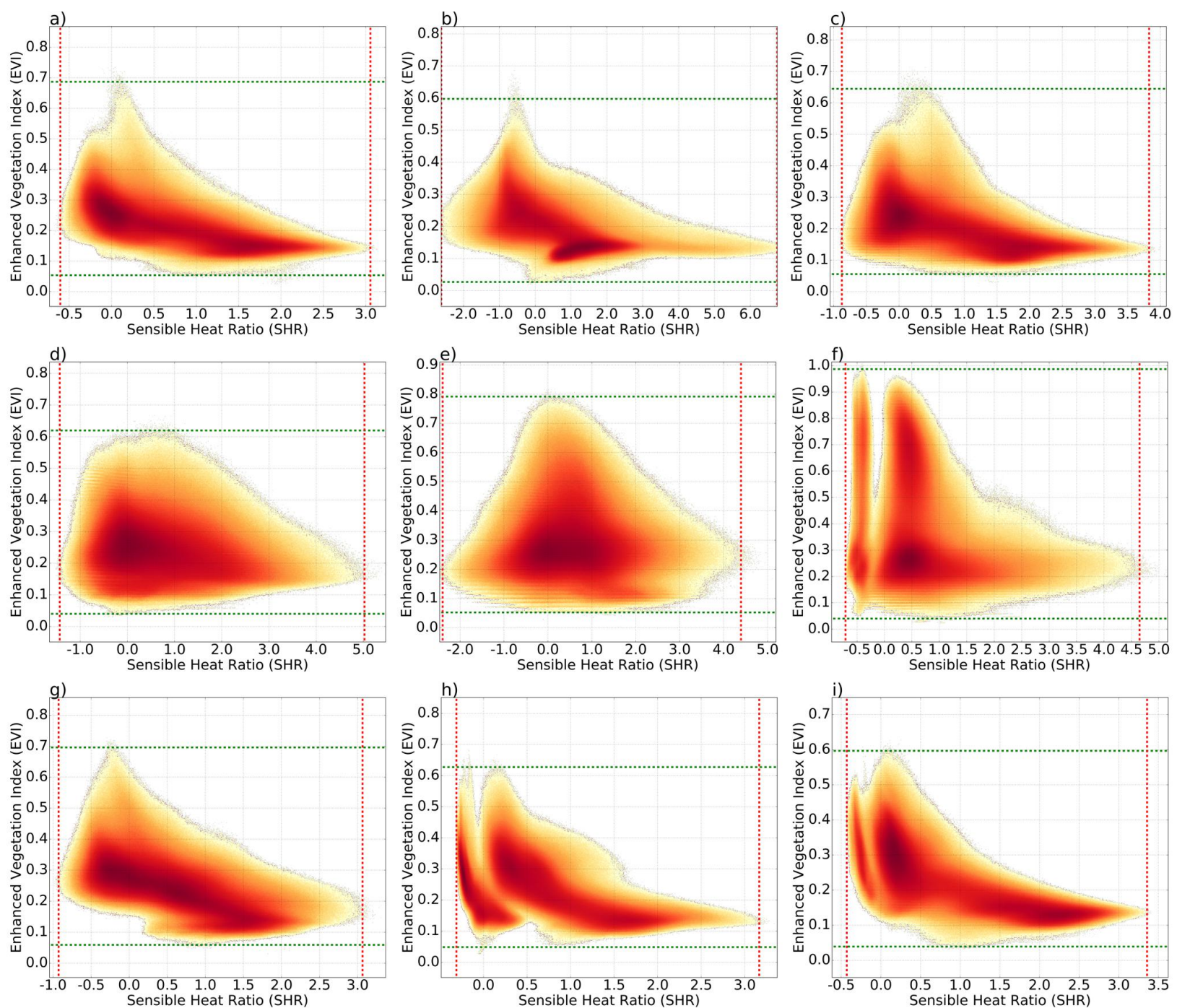

Figure 5: Sensible Heat Triangles (SHT) showing the density distribution of the Sensible Heat Ratio (SHR) to the Enhanced Vegetation Index (Vegetation Fraction) for a) 17 Nov 2006, b) 5 Feb 2007, c) 9 Mar 2007, d) 26 Apr 2007, e) 12 May 2007, f) 1 Sep 2007, g) 8 Dec 2008, h) 25 Jan 2009 and j) 26 Feb 2009, where darker colours indicated higher densities. The horizontal dashed lines were the derived upper and lower limits of vegetation cover, while the vertical dashed lines represented the derived upper and lower limits of evaporative energy.

All SHT plots had a consistent shape and form across the nine Canberra acquisition dates, with a distinctive vertex denoting the boundary for $S H R_{M A X}$ (right-hand side) and long flat edge denoting the boundary for $S H R_{M I N}$ (left-hand side) (Fig. 5). The $S H T$ plots for 1 Sep 2007, 25 Jan 2009, and 26 Feb 2009 had two separate and distinct distribution clusters near the left edge (Fig. 5), the cool and wet $S H R$ boundary. These patterns were spatially coincident with low wind speeds, $<1 \mathrm{~m} \mathrm{~s}^{-1}$, that led to comparatively large $R_{A H}$ values near relevant ground stations for each date. Comparatively high stage one $T_{S}$ offsets (7.89 $K$ and $10.77 K$ respectively) were also recorded for these dates (Table 1$)$. Also, 
for the larger 1 Sep 2007 SHT disconnection, the effect was spatially coincident with a comparatively small $R_{A H}$ and a comparatively large $T_{S}$ to $T_{A}$ difference surrounding the snow covered alpine areas, common for early September in the Australian Alps. The 5 Feb 2007 SHT plot exhibited a distinct density cluster midway along the lower edge of the $S H T$ (Fig. 5), spatially coincident with stable $S H R$ and $R_{A H}$ values in the agricultural and grazing areas in the north-west corner of the Canberra study area (Fig. 1). The 5 Feb 2007 $S H T$ plot also had the only negative $T_{S}$ offset and the highest $B_{E R}$ coefficient across the nine Canberra acquisition dates (Fig. 2a and Table 1).

\subsection{Sensitivity of SEBS and SEBS-ER to Input Error}

Compared to SEBS, SEBS-ER showed less sensitivity to perturbation for each of the six input variables analysed $\left(T_{S}, T_{A}, \delta, Z_{O M}, U_{x}\right.$, and $\left.P_{v a p}\right)$ (Fig. 6). Overall, SEBS and SEBS-ER were more sensitive to the variation of $T_{S}, T_{A}$, and $\delta$ than $Z_{O M}, U_{x}$, and $P_{v a p}$ (Fig. 6 and Fig. 7). However, SEBS-ER showed residual variation in $\lambda E$ when variation in the input variable was zero (Fig. 6), while apart from $T_{S}$, SEBS indicated no residual variation in $\lambda E$ across input variables (Fig. 6). Individually, SEBS-ER had substantially lower sensitivity in $\lambda E$ values for $T_{S}$, moving from $-5.37 \mathrm{~W} \mathrm{~m}^{-2}$ to $-1.67 \mathrm{~W} \mathrm{~m}^{-2}$ per percent change in $T_{S}$ (Fig. 6). Similarly, SEBS-ER was substantially less sensitive than SEBS to changes in $T_{A}$, moving from $4.30 \mathrm{~W} \mathrm{~m}^{-2}$ to $1.59 \mathrm{~W} \mathrm{~m}^{-2}$ per percent change in $T_{A}$ (Fig. 6). The sensitivity distribution pattern for $T_{S}$ and $T_{A}$ varied slightly between acquisition dates, indicated by comparatively lower $R^{2}$ values (Fig. 6). The sensitivity of SEBS to $\delta$ was similar to that of $T_{S}$, with a change of $5.67 \mathrm{~W} \mathrm{~m}^{-2}$ per percent change in $\delta$. The coherence, among acquisition dates, in the response to $\delta$ perturbation was strong with comparatively high $R^{2}$ values (Fig. 6). The sensitivity of SEBS-ER to $\delta$ was about two thirds that of SEBS, at $3.81 W \mathrm{~m}^{-2}$ per percent change in $\delta$.

While overall the $\lambda E$ sensitivity of SEBS and SEBS-ER were lower for $Z_{O M}, U_{x}$ and $P_{v a p}$, the comparative relationship between SEBS and SEBS-ER was similar to $T_{S}, T_{A}$ and $\delta$. For both SEBS and SEBS-ER, the variation in $\lambda E$ sensitivity among acquisition dates and $30 \mathrm{x}$ $30 \mathrm{~m}$ land units were the largest for $U_{x}$ and $Z_{O M}$, highlighted by lowest $R^{2}$ statistics (Fig. 6). The sensitivity response distributions were also similar for $U_{x}$ and $Z_{O M}$ with SEBS-ER showing asymmetrically greater variation in sensitivity for a negative shift in $U_{x}$ and $Z_{O M}$ input values. For both $U_{x}$ and $Z_{O M}$, the reduction in sensitivity to perturbations was just above $50 \%$ for SEBS-ER, compared to SEBS (Fig. 6). SEBS and SEBS-ER were least sensitive to perturbations in $P_{v a p}$, per percent change, with $\lambda E$ changes of just $0.372 \mathrm{Wm}^{-2}$ 


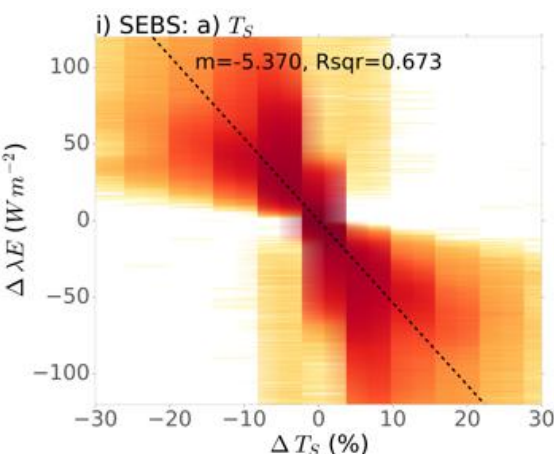

ii) SEBS-ER: a) $T_{S}$
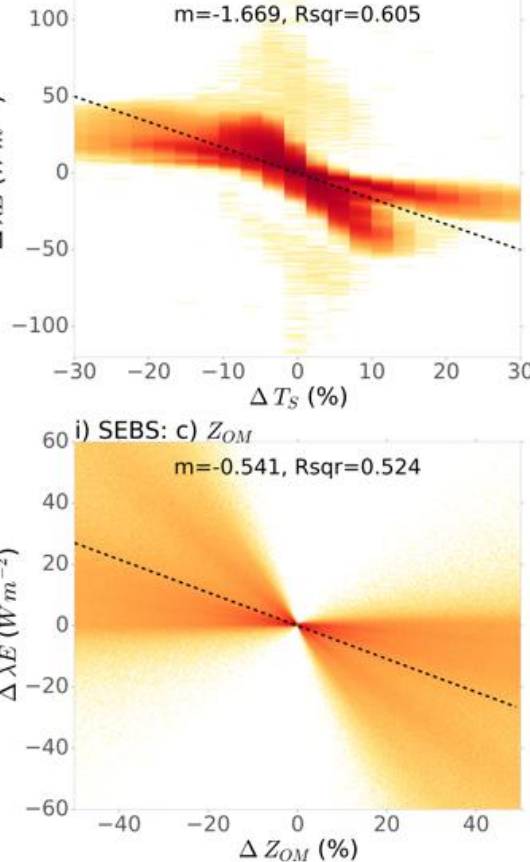

60 ii) SEBS-ER: c) $Z_{O M}$

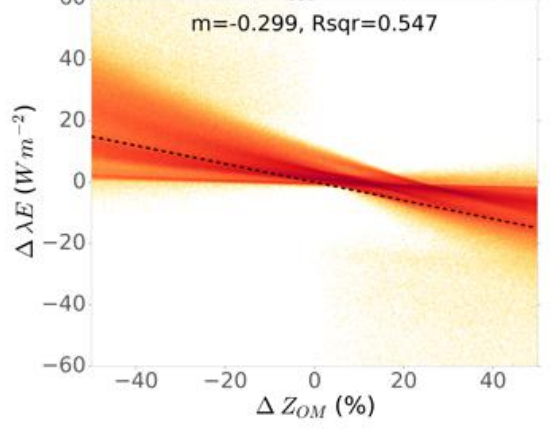

i) SEBS: b) $T_{A}$

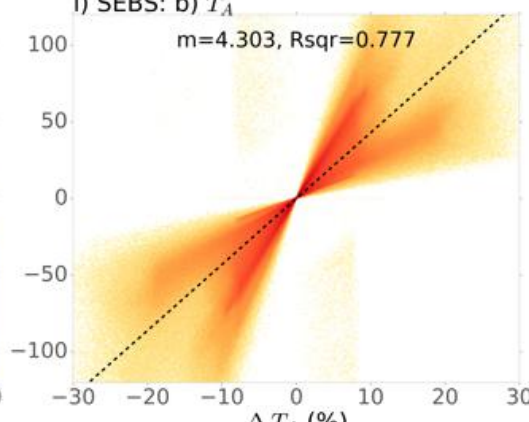

ii) SEBS-ER: b) $T_{A}$

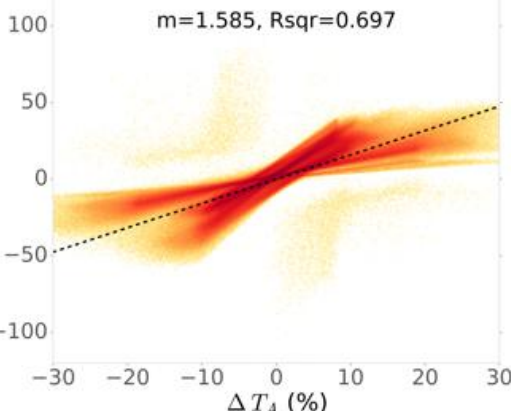

60 i) SEBS: f) $U_{x}$

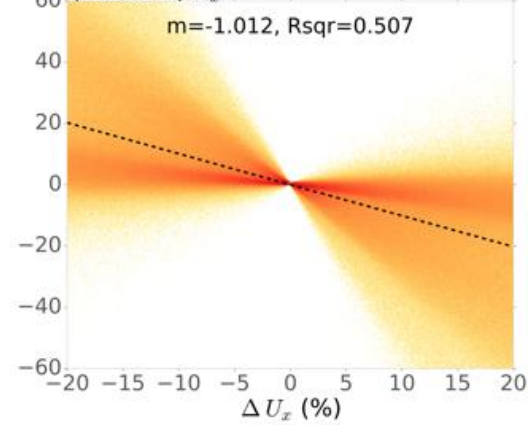

60 ii) SEBS-ER: f) $U_{x}$

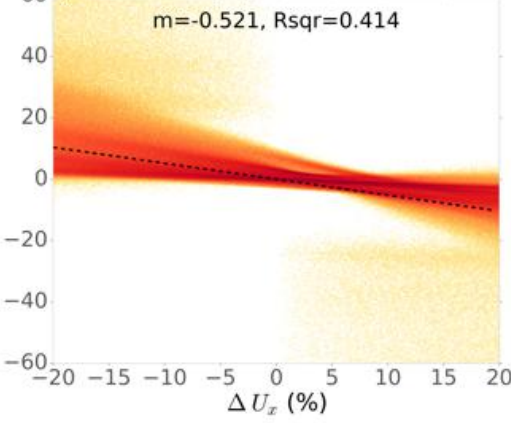

i) SEBS: d) $\delta$ $m=5.667$, Rsqr $=0.959$

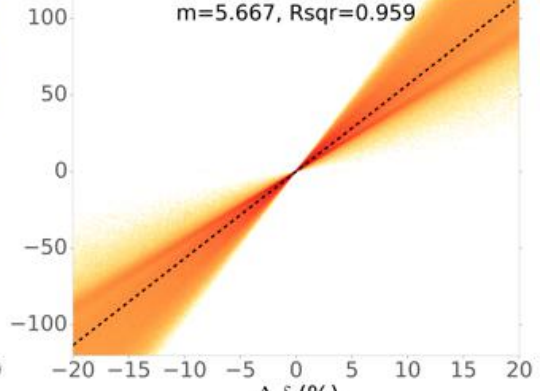

$\Delta \delta(\%)$

ii) SEBS-ER: d) $\delta$

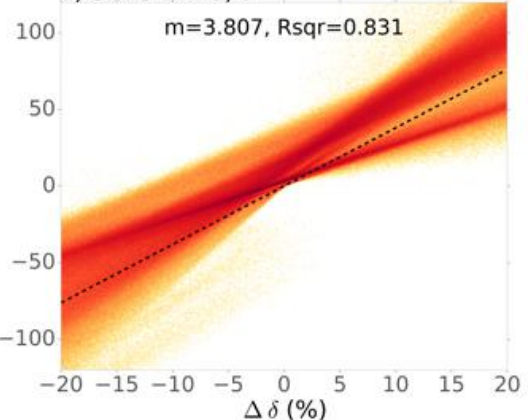

60 i) SEBS: e) $P_{\text {vap }}$

$\mathrm{m}=0.372, \mathrm{Rsqr}=0.983$

40

20

0

$-20$

$-40$

$\begin{array}{lllllll}-60 & -20 & -15 & -10 & -5 & 0 & 0 \\ \Delta P_{\text {trup }}(\%) & 10 & 15 & 20\end{array}$ 60 ii) SEBS-ER: e) $P_{\text {tap }}$

$\mathrm{m}=0.238$, $\mathrm{Rsqr}=0.856$

40

20

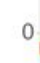

$-20$

$-40$

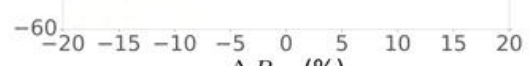

Figure 6: Temporally averaged comparisons of $\lambda E$ input sensitivity for i) SEBS and ii) SEBS-ER surface energy balance algorithms after perturbing different input variables: a) surface temperature $\left(T_{S}\right)$; b) air temperature $\left.\left(T_{A}\right) ; \mathrm{c}\right)$ daily solar exposure $\left.(\delta) ; \mathrm{d}\right)$ surface roughness $\left(Z_{O M}\right)$; e) wind speed $\left(U_{x}\right)$; and $\left.\mathrm{f}\right)$ vapour pressure $\left(P_{v a p}\right)$, where darker shading represented higher densities. Linear regressions between the change in $\lambda E$ to the $\%$ change of each input parameter were represented by dashed black lines, with the gradient coefficient $(\mathrm{m})$ and $R^{2}$ statistic displayed at the top of each density plot.

for SEBS and $0.238 W \mathrm{~m}^{-2}$ for SEBS-ER. Of the six input variables, $P_{v a p}$ sensitivity was also the most coherent for SEBS and SEBS-ER, among acquisition dates and $30 \times 30 \mathrm{~m}$ land units. 
i) SEBS: a) $T_{S}$

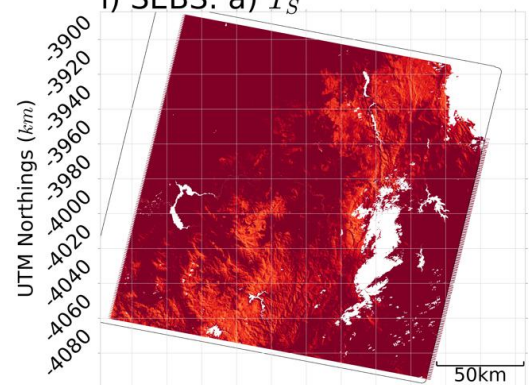

ii) SEBS-ER: a) $T_{S}$

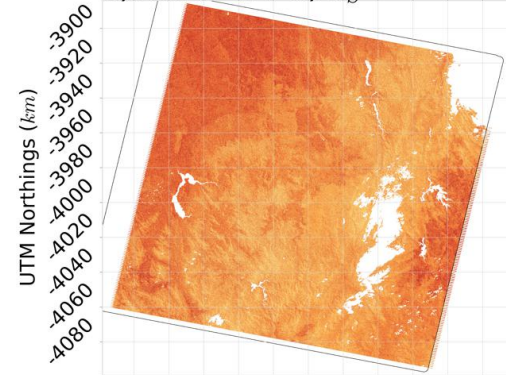

i) SEBS: d) $Z_{O M}$

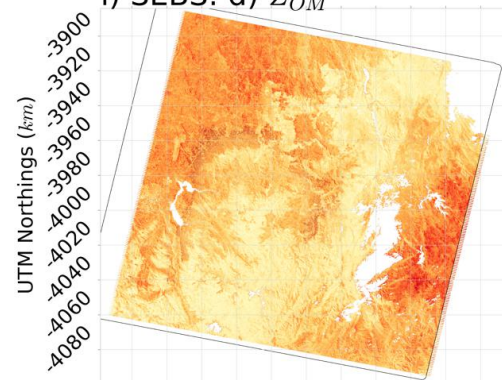

ii) SEBS-ER: d) $Z_{O M}$

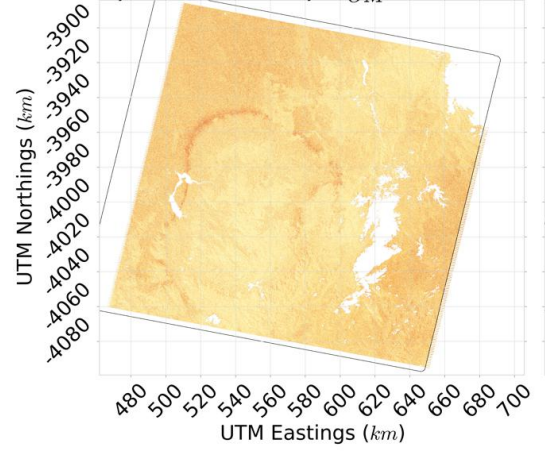

i) SEBS: b) $T_{A}$

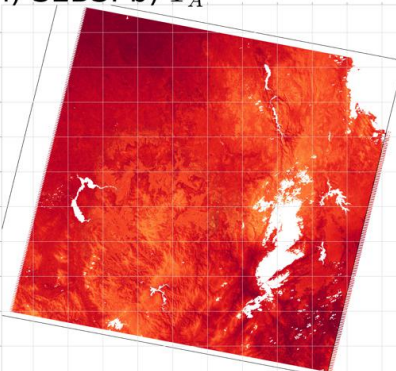

ii) SEBS-ER: b) $T_{A}$

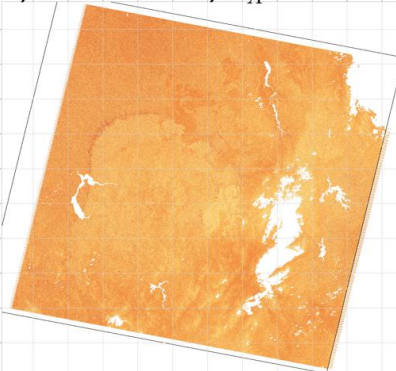

i) SEBS: e) $U_{x}$

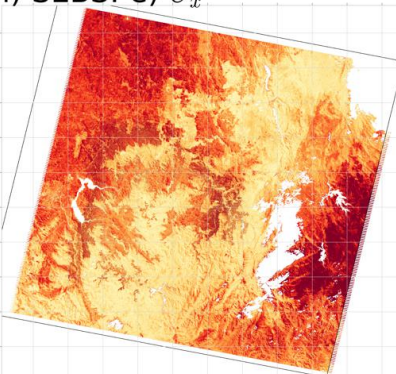

ii) SEBS-ER: e) $U_{x}$

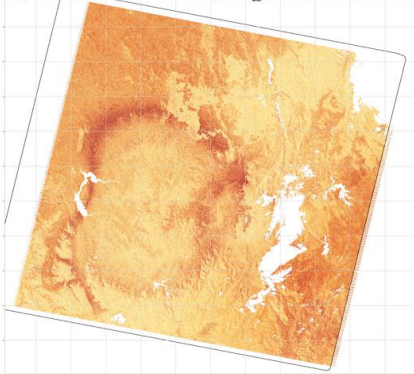

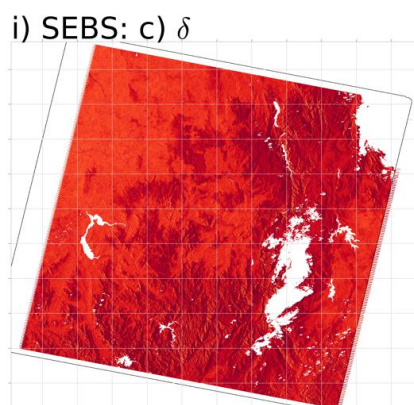

ii) SEBS-ER: c) $\delta$

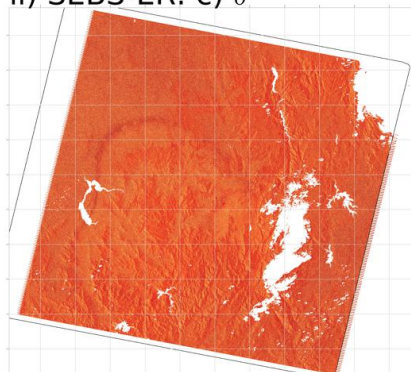

i) SEBS: f) $P_{v a p}$

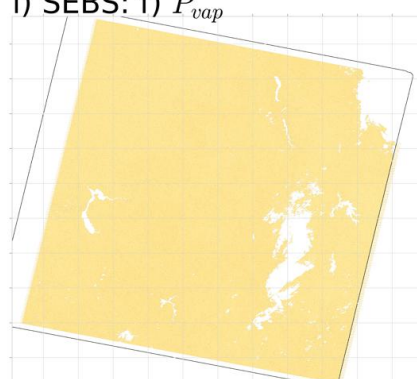

ii) SEBS-ER: f) $P_{v a p}$

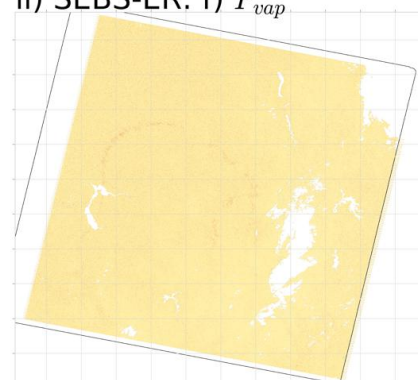

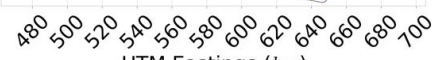
UTM Eastings $(\mathrm{km})$

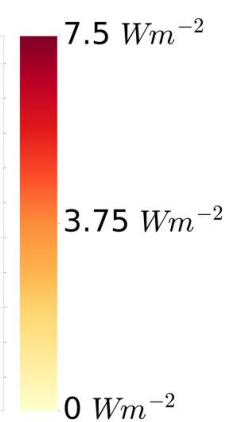

$7.5 \mathrm{Wm}^{-2}$

$3.75 W^{-2}$

$0 W^{-2}$

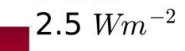

$0 \mathrm{Wm}^{-2}$

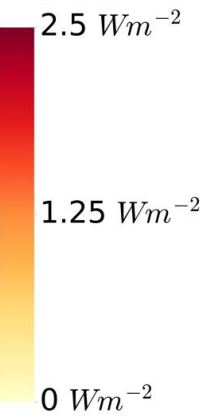

$1.25 W^{-2}$ UTM Eastings $(\mathrm{km})$

Figure 7: Temporally averaged spatial grids of $\lambda E$ sensitivity from perturbation in (i) SEBS and (ii) SEBSER input variables in the Canberra study area (black polygon). Grids show the relative spatial change in $\lambda E$ related to a $1 \%$ change in (a) surface temperature $\left(T_{S},{ }^{\circ} \mathrm{C}\right)$, (b) air temperature $\left(T_{A},{ }^{\circ} \mathrm{C}\right),(\mathrm{c})$ solar exposure $\left(\delta, M J d a y^{-1}\right),(\mathrm{d})$ surface roughness for momentum $\left(Z_{O M}, m\right)$, (e) wind speed $\left(U_{x}, m s-1\right)$, and (f) vapour pressure $\left(P_{\text {vap }}, k P a\right)$. Note the scale change between $T_{S}, T_{A}$ and $\delta\left(0-7.5 \mathrm{Wm}^{-2}\right)$ and $Z_{O M}, U_{x}$ and $P_{v a p}$ $\left(0-2.5 \mathrm{~W} \mathrm{~m}^{-2}\right)$. UTM Eastings and Northings were for Zone 55 North.

Average spatial grids of $\lambda E$ sensitivity (per percent input change) to perturbations in $T_{S}, T_{A}, \delta, Z_{O M}, U_{x}$, and $P_{v a p}$ (Fig. 7) reflected the sensitivity distributions (Fig. 6), with consistently lower sensitivities by SEBS-ER, compared to SEBS. The spatial grids also reinforced the difference in magnitude between $T_{S}, T_{A}$, and $\delta$ inputs, compared to $Z_{O M}$, 
$U_{x}$, and $P_{v a p}$ inputs (Fig. 7). For SEBS, the sensitivity to $T_{S}$ was smaller in forested areas than agricultural or grazing areas (Fig. 1 and Fig. 7). This pattern was substantially less pronounced in the SEBS-ER $T_{S}$ sensitivity grid, featuring a more spatially uniform sensitivity response (Fig. 7). Similarly, the $T_{A}$ sensitivity response was greater in the north-west and south-east corners of the study area, while the SEBS-ER $T_{A}$ sensitivity grid was spatially uniform (Fig. 7). The SEBS $\delta$ sensitivity grid exhibited a high response in forested areas compared to agricultural, grassland, or grazing land types. Like $T_{S}$ and $T_{A}$, the $\delta, Z_{O M}$, $U_{x}$, and $P_{\text {vap }}$ sensitivity response grids for SEBS-ER were spatially uniform and smaller in magnitude than SEBS (Fig. 7). Also, like the sensitivity distribution plots in Figure 6, the SEBS $Z_{O M}$ and $U_{x}$ sensitivity spatial grids indicated similar spatial patterning, with increased sensitivity along the low vegetation height land types along the eastern boundary and in the north-west corner of the study area (Fig. 1 and Fig. 7). Finally, compared to the other input variables, $P_{\text {vap }}$ exhibited a negligible and spatially uniform sensitivity grid for SEBS, also indistinguishable from that of SEBS-ER (Fig. 7).

\subsection{Validation and Performance of SEBS and SEBS-ER}

Using all available $\lambda E$ measurements from the two eddy covariance flux towers (Fig. 1), we compared the accuracy of the SEBS and SEBS-ER surface energy balance algorithms (Fig. 8, Fig. 9, Table 2, and Table 3). Among the four algorithms validated using the Tumbarumba and Nimmo High Plains flux towers, SEBS-ER produced the smallest RMSE and the highest $R^{2}$ (Table 2 ) at each tower, and the smallest RMSE and highest $R^{2}$ overall (Table 3). Using an F test, SEBS-ER also showed a significant increase in performance $(<0.05)$ from SEBS when calculated from all 12 flux tower comparisons. At the forested Tumbarumba flux tower, both SEBS and SEBS-ER varied in their estimates of $\lambda E$ among dates, both above and below the observed flux tower values (Fig. 8), however, SEBS-ER was substantially more accurate, with a RMSE of just $62.3 \mathrm{~W} \mathrm{~m}^{-2}$ compared to an RMSE of $110.8 \mathrm{~W} \mathrm{~m}^{-2}$ for SEBS (Table 2). The HTEM algorithm produced an RMSE slightly greater than SEBS $\left(133.0 \mathrm{~W} \mathrm{~m}^{-2}\right)$ and the S-SEBI algorithm produced the largest RMSE of $\lambda E$ (148.2 $\mathrm{W} \mathrm{m}^{-2}$ ) (Table 2). Comparing the nine acquisition dates, SEBS-ER produced the closest $\lambda E$ estimate for seven (5 Feb 2007, 9 Mar 2007, 26 Apr 2007, 12 May 2007, 8 Dec 2008, 25 Jan 2009 and 26 Feb 2009), with SEBS producing the nearest $\lambda E$ estimate on 17 Nov 2006 and 1 Sep 2007 (Fig. 8). On four dates (9 Mar 2007, 26 Apr 2007, 12 May 2007 and 8 Dec 2008), SEBS-ER produced very close $\lambda E$ estimates that were less than $30 \mathrm{Wm}^{-2}$ from Tumbarumba flux tower observations, producing an RMSE of just $13.4 \mathrm{~W} \mathrm{~m}^{-2}$ across 

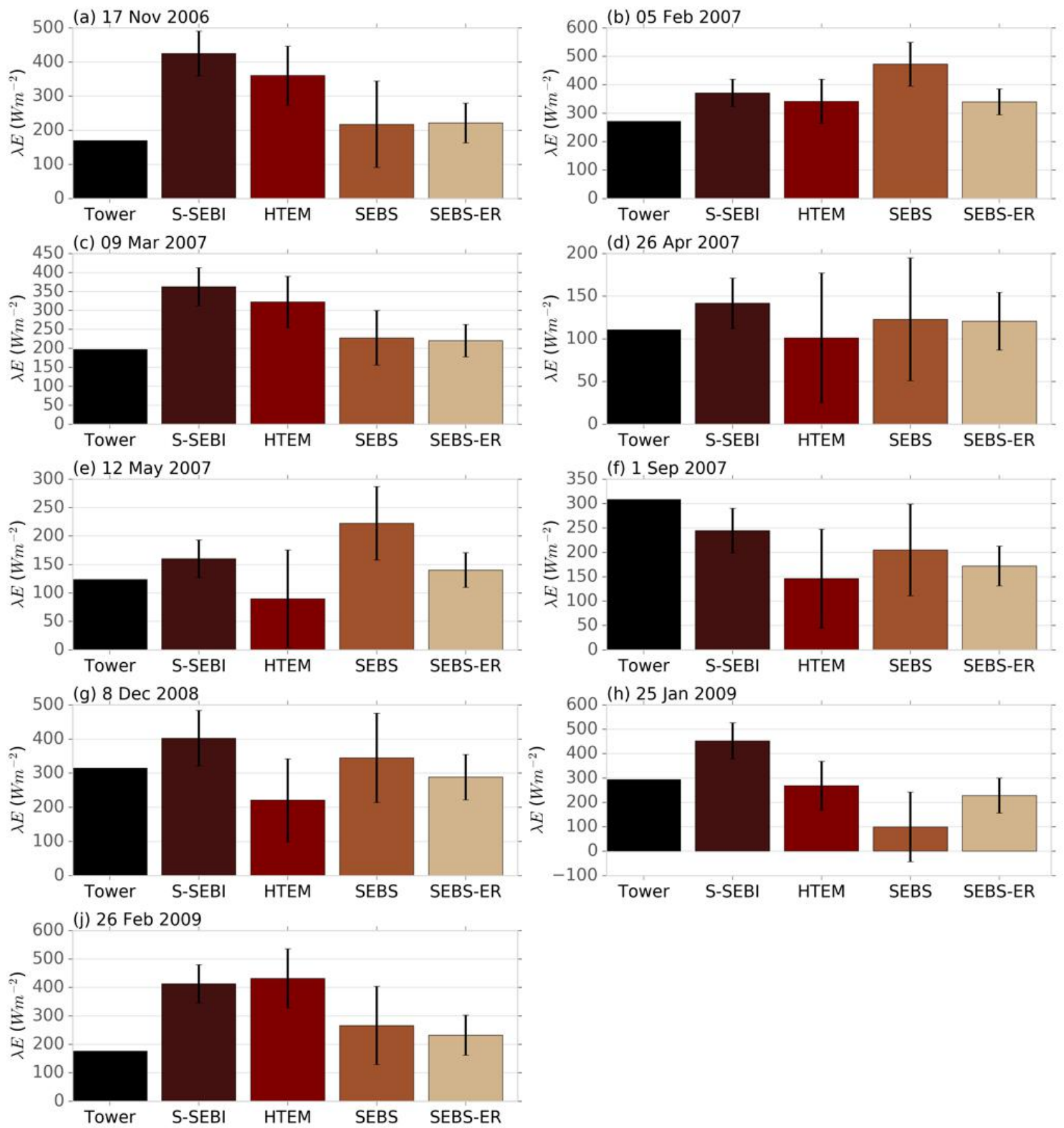

Figure 8: $750 m$ radial samples of $\lambda E\left(W m^{-2}\right)$ ( \pm 2 SD) from S-SEBI and HTEM (Webster et al., 2016) and SEBS and SEBS-ER, compared to $\lambda E$ observed at the Tumbarumba flux tower (black) (Fig. 1) for the nine acquisition dates: (a) 17 Nov 2006; (b) 5 Feb 2007; (c) 9 Mar 2007; (d) 26 Apr 2007; (e) 12 May 2007; (f) 1 Sep 2007; (g) 8 Dec 2008; (h) 25 Jan 2009; and (j) 26 Feb 2009.

these four dates. For all three acquisition dates available for comparison at the Nimmo High Plains flux tower, SEBS-ER $\lambda E$ were closer to the flux tower estimate than SEBS (Fig. 9), with RMSE's of $32.2 \mathrm{~W} \mathrm{~m}^{-2}$ and $80.6 \mathrm{~W} \mathrm{~m}^{-2}$ respectively (Table 2 ). In the sub-alpine grassland land cover, the RMSE's for S-SEBI $\left(50.3 \mathrm{~W} \mathrm{~m}^{-2}\right)$ and HTEM $\left(41.8 \mathrm{~W} \mathrm{~m}^{-2}\right)$ were lower than SEBS but larger than SEBS-ER (Table 2). All four algorithms overestimated 


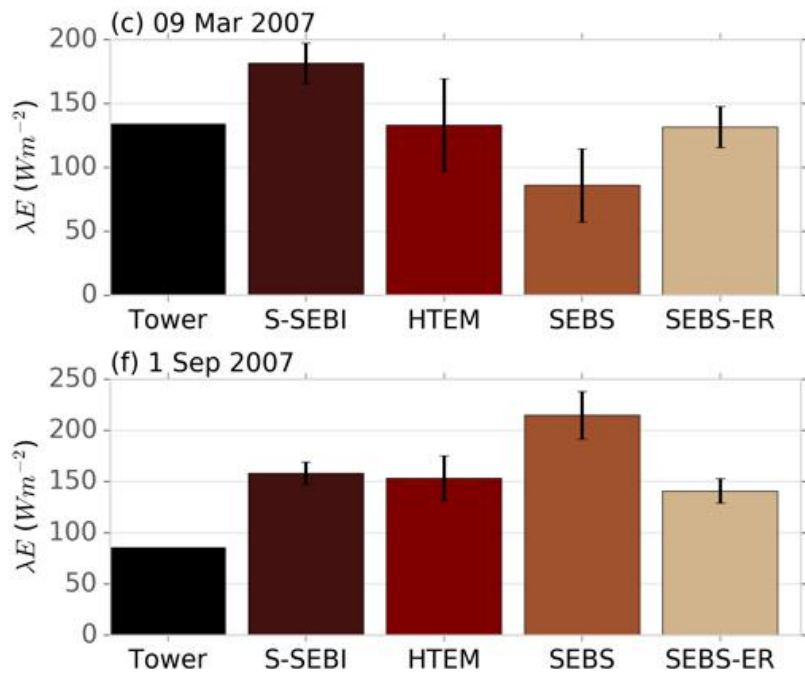

(e) 12 May 2007

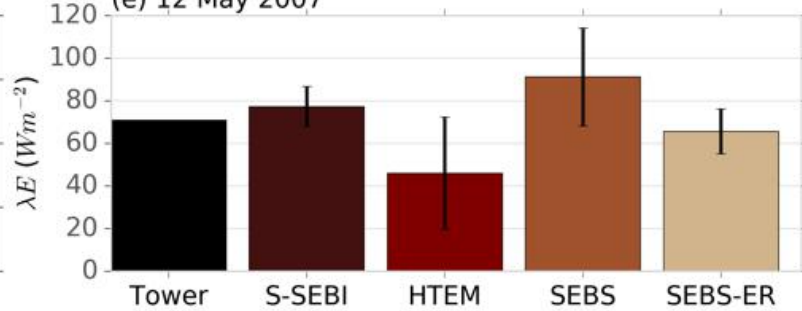

Figure 9: $30 m$ radial samples of $\lambda E\left(W m^{-2}\right)$ ( \pm 2 SD) from S-SEBI and HTEM (Webster et al., 2016) and SEBS and SEBS-ER, compared to $\lambda E$ observed at the Nimmo High Plains flux tower (black) (Fig. 1) for three acquisition dates: (c) 9 Mar 2007; (e) 12 May 2007; and (f) 1 Sep 2007.

Table 2: $\lambda E$ RMSE $\left(W m^{-2}\right)$ and $R^{2}$ of S-SEBI, HTEM, SEBS, and SEBS-ER surface energy balance algorithms for all acquisition dates compared to the a) Tumbarumba and b) Nimmo High Plains flux towers.

\begin{tabular}{llllll} 
Tower & Metric & S-SEBI & HTEM & SEBS & SEBS-ER \\
\hline \multirow{2}{*}{)} & RMSE & $148.2 W m^{-2}$ & $133.0 W m^{-2}$ & $110.8 W m^{-2}$ & $62.3 W^{-2}$ \\
& $R^{2}$ & 0.819 & 0.772 & 0.824 & 0.879 \\
\hline \multirow{2}{*}{ b) } & RMSE & $50.3 W m^{-2}$ & $41.8 W m^{-2}$ & $80.6 W m^{-2}$ & $32.2 W m^{-2}$ \\
& $R^{2}$ & 0.881 & 0.879 & 0.685 & 0.939 \\
\hline
\end{tabular}

Table 3: Overall $\lambda E$ RMSE $\left(W m^{-2}\right), R^{2}$, and F statistic between SEBS and SEBS-ER for all 12 flux tower comparisons.

\begin{tabular}{llll}
\hline Algorithm & RMSE & $R^{2}$ & SEBS $\rightarrow$ SEBS-ER F stat (P value) \\
\hline SEBS & $104.1 W^{-2}$ & 0.812 & $3.42(0.02651)$ \\
SEBS-ER & $56.3 \mathrm{~W} \mathrm{~m}^{-2}$ & 0.925 & \\
\hline
\end{tabular}

\subsection{Temporal Stability of SEBS and SEBS-ER}

Averaged over the 52 acquisition dates and compared to SEBS $E T_{a}$ outputs, SEBS-ER exhibited substantially lower RMSE both spatially and seasonally, compared to the daily 
a) SEBS $E T_{a}$ RMSE
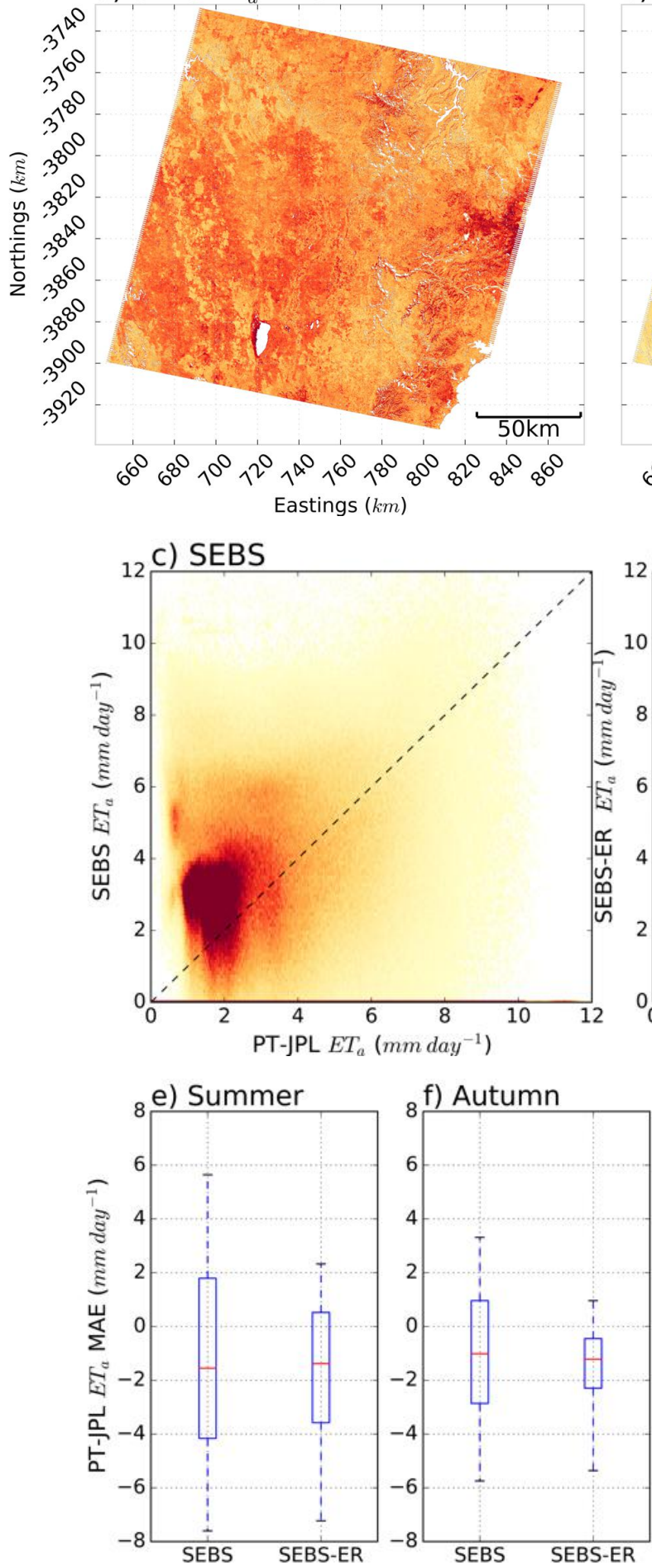

b) SEBS-ER $E T_{a}$ RMSE

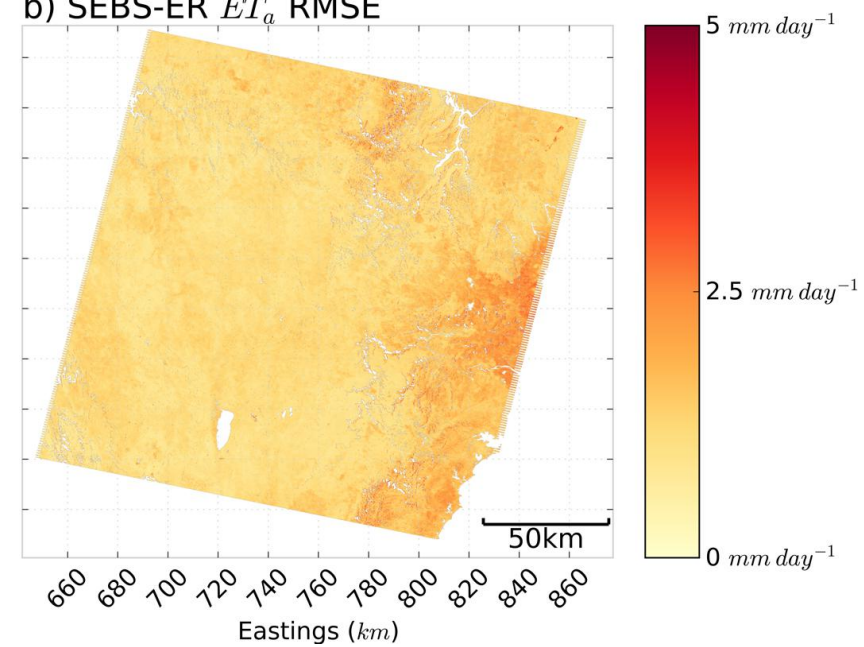

d) SEBS-ER

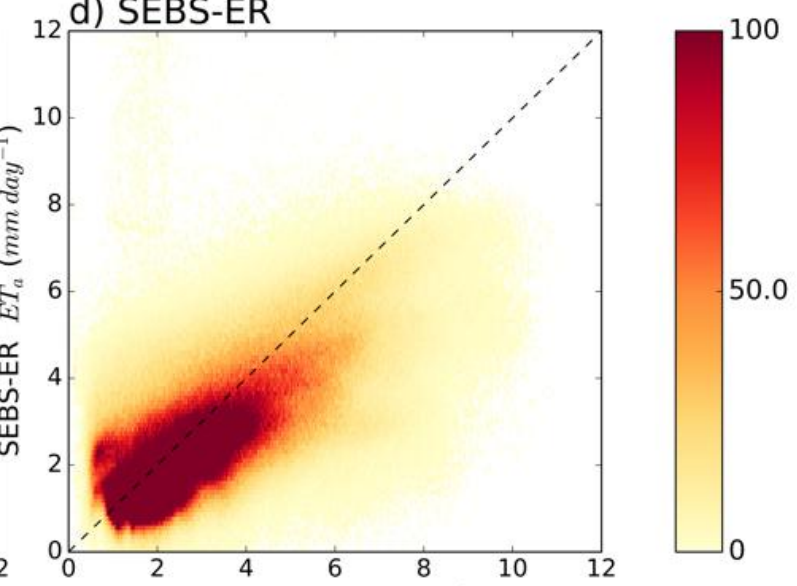

PT-JPL ETa $\left(m m d a y^{-1}\right)$
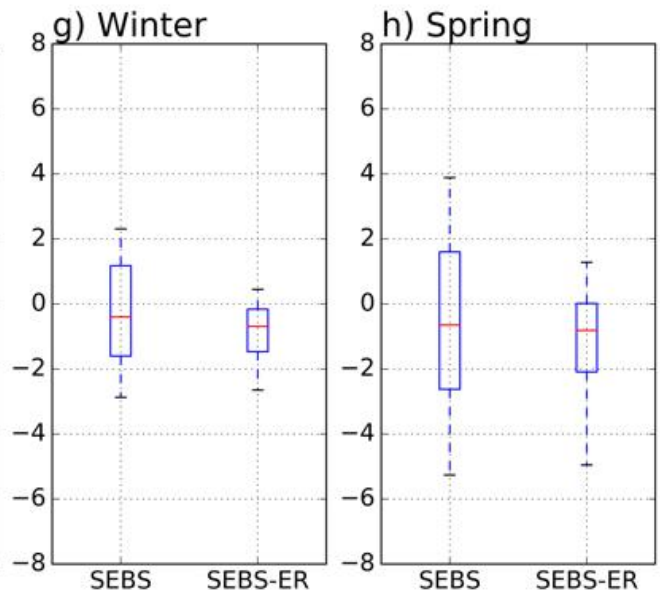

Figure 10: Multifaceted comparison of SEBS and SEBS-ER $E T_{a}$ to daily PT-JPL $E T_{a}$ data, showing the temporal average root mean square error (RMSE) spatially $\left(m m d a y^{-1}\right)$ of (a) SEBS and (b) SEBS-ER and the comparisons of density distributions between PT-JPL $E T_{a}$ to (c) SEBS $E T_{a}$ and (d) SEBS-ER $E T_{a}$. Seasonal differences in SEBS and SEBS-ER $E T_{a}$, compared to PT-JPL $E T_{a}$ were captured in estimates of mean absolute error (MAE), ( $m m d^{d a y^{-1}}$ ) for acquisitions in (e) summer, (f) autumn, (g) winter, and (h) spring. 
archive of PT-JPL data (Fig. 10). Additionally, SEBS-ER had greater coherence over the range of PT-JPL $E T_{a}$ data, with SEBS generally overestimating $E T_{a}$ compared to PT-JPL $E T_{a}$ data (Fig. 10). In the RMSE spatial grids, SEBS $E T_{a}$ error was greater over non-forested areas of the Sydney study area, with SEBS-ER exhibiting a spatially uniform distribution of error (Fig. 10). Seasonally, compared to SEBS and referenced to PT-JPL ET data, SEBS-ER had less variation in mean absolute error (MAE) in summer and substantially reduced variation in MAE in autumn, winter, and spring (Fig. 10). Across the seasons, as indicated by MAE, SEBS-ER generally underestimated PT-JPL ET $T_{a}$ estimates, while SEBS overestimated in winter, underestimated in summer and spring, and was on parity in autumn (Fig. 10).

Also in the Sydney study area (Fig. 1), SEBS-ER reduced $E T_{a}$ overestimation exhibited by SEBS when compared to pan evaporation data (Fig. 11) from two meteorological ground stations across cloud free acquisition dates. However, both SEBS and SEBS-ER were prone to overestimating $E T_{a}$ when compared to smaller $E T_{o}$ pan evaporation observations. Between the two pan evaporation stations, compared values and errors were evenly spread, with no discernible difference in input $\left(E T_{o}\right)$ or estimated $\left(E T_{a}\right)$ magnitudes (Fig. 11).
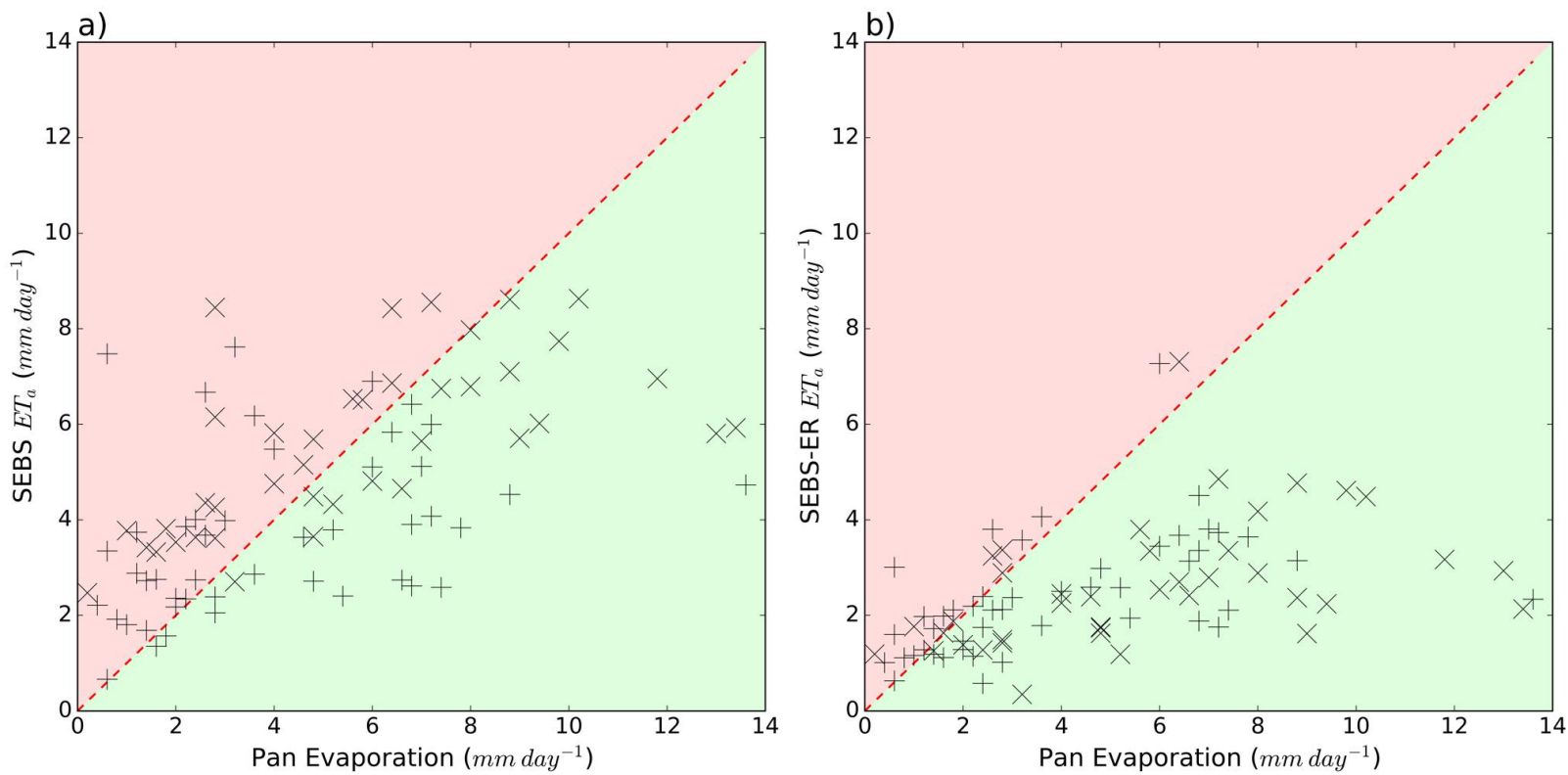

Figure 11: Daily pan evaporation data $\left(m m d a y^{-1}\right)$ from stations (x) 070014 and (+) 070263 in the Sydney study area (Fig. 1) over a ten year period (Fig. 2b) compared to actual evapotranspiration $\left(E T_{a}, m m d a y^{-1}\right)$ from (a) SEBS and (b) SEBS-ER. The red shaded area indicates unrealistic estimates of SEBS and SEBS-ER $E T_{a}$ and the green shaded area indicates valid SEBS and SEBS-ER $E T_{a}$ estimates. 


\section{Discussion}

The addition of an energy restraint to SEBS (Su, 2002) within the MoninObukhov iterative correction to $H$ was largely successful. SEBS-ER effectively resolved energy fluxes from nine Landsat acquisitions in the Canberra study area (Fig. 2a) and energy fluxes from 52 Landsat acquisitions from the Sydney study area (Fig. 2b). Compared to SEBS, SEBS-ER improved resilience to perturbation from six input variables (Fig. 6 and Fig. 7), produced significantly greater accuracy at two flux tower locations (Table 2, and Table 3), and provided greater temporal stability against pan evaporation data (Fig. 11) and a daily PT-JPL $E T_{a}$ dataset (Fig. 10).

\subsection{Development of the SEBS energy restraint}

$T_{S^{-}} V I \mathrm{SEB}$ techniques have developed a considerable amount in recent years (Gampe et al., 2016; Knipper et al., 2016; Lian and Huang, 2016; Long and Singh, 2012; Long et al., 2012; Yang and Shang, 2013), but our SEBS-ER approach is the first implementation of a direct flux based energy restraint, within a domain based triangular framework. Unlike other triangular (Gampe et al., 2016; Knipper et al., 2016) or trapezoidal (Long and Singh, 2012) techniques, our energy restraint used the Penman-Monteith formulation (Liang et al., 2014) in SEBS $(\mathrm{Su}, 2002)$, removing the assumption that $\lambda E=A E$ at the cold and wet boundary. This makes SEBS-ER preferable for SEB applications in water limited environments (Zhang et al., 2008a).

The scene wide adjustment of $T_{S}$ for the derivation of $H_{E}$ within the first stage of the energy restraint does not compromise the information contained within the final SEBS-ER $E T_{a}$ product. It is comparable to, and an extension of, the process with which satellite brightness temperature is atmospherically corrected to estimate $T_{S}$ and the spatial detail/relationship between neighbouring land units is not compromised. Similarly, the second stage SHT analysis acts to globally stretch the distribution of $H$ data between the limits of $A E$ and $H_{\text {wet }}$, its execution is directly comparable to the CIMEC (calibration using inverse modeling at extreme conditions) process employed within METRIC and SEBAL (Allen et al., 2013).

Improved applicability of domain based calibration techniques are dependent on scales of implementation (Long and Singh, 2013). Platform dependent scale dependencies (McCabe and Wood, 2006) are critical for further deployment of the SEBS-ER model as domain and resolution dependencies can lead to mean absolute percentage difference (MAPD) in $\Lambda$ of up to $50 \%$ (Long et al., 2012). Additionally, the ability to define the boundary pixels at 
coarse scales $\left(>250 \mathrm{~m}\right.$ ) becomes difficult within triangular $E T_{a}$ frameworks (Zhang et al., 2008b) although, while the boundaries of the triangular framework may shift with domain size, the underlying spatial pattern remains consistent (Tian et al., 2013). Ultimately, these domain and scale based dependencies need to be addressed and tested before SEBS-ER can be confidently operated outside of the domain and scale of a $30 \mathrm{~m}$ Landsat tile.

A distinct difference between SEBS and SEBS-ER relates to the appropriate identification of clean and uncontaminated vegetated land units within the multispectral image scene. While SEBS does not rely on the surrounding 30 x $30 \mathrm{~m}$ land units (Su, 2002), SEBS-ER needs these surrounding units to define the limiting boundaries, $S H R_{M I N}$ and $S H R_{M A X}$. Thus, inaccurate identification and masking of cloud, cloud shadow, snow cover, water bodies, sensor anomalies, urban areas, and steep terrain will likely alter the scenewide distribution of $T_{S}$, creating bias within the derivation of $S H R_{M I N}$ and $S H R_{M A X}$ that will reduce accuracy within SEBS-ER ET estimates. Also, SEBS-ER would be particularly sensitive if cloud contaminated an area strongly representative of either the wet or dry edge of the $S H T$ (Long et al., 2012), biasing $\lambda E$ values, increasing positively if the cold and wet edge $\left(S H R_{M I N}\right)$ were obscured and increasing negatively if the hot and dry edge $\left(S H R_{M A X}\right)$ were obscured. Further complicating analyses, not all SEB applications focus on areas equivalent to that of a Landsat image tile (approx $185 \mathrm{~km} \times 185 \mathrm{~km}$ ) (Evett et al., 2012; Long et al., 2012). Within the developed SEBS-ER energy restraint, the image processing constants derived for the identification of the upper and lower boundaries for $S H R$ were manually optimised to suit the domain size and pixel resolution for that of a Landsat scene with between 0 and 30 percent cloud contamination and no Landsat 7 striping effects. While capability to specify a region of interest or employ SEBS-ER with alternative sensors requires alteration of the current SEBS-ER image search function (Fig 4), this would be a practical addition to the currently static SEBS-ER framework, enabling the production of more targeted and localised SEB products.

\subsection{Sensitivity of SEBS and SEBS-ER to input error}

SEBS-ER has improved stability and resilience, compared to SEBS, in its estimation of $\lambda E$ when we perturbed remotely sensed and meteorological inputs. The most substantial sensitivity reduction was for temperature inputs, $T_{S}$ and $T_{A}$. This was important because there is substantial uncertainty in their estimation (Li et al., 2013; McVicar et al., 2007), particularly in heterogeneous landscapes (Vanwalleghem and Meentemeyer, 2009). Also, $T_{S}$ and $T_{A}$ are key inputs to the estimation of $H$ and $\lambda E$ in SEBS and SEBS-ER, causing in- 
teraction and exaggeration of their individual sensitivities (Yang and Shang, 2013). Overall, the reduced sensitivity of SEBS-ER is useful, improving resilience in estimated SEB fluxes from input errors and bias. Furthermore, SEBS-ER provided a more spatially uniform sensitivity response to each of the six remotely sensed and meteorological inputs, removing the variation in errors associated with landscape heterogeneity created by varying vegetation height and type (Kalma et al., 2008; Su, 2002; Timmermans et al., 2013).

Our sensitivity analysis for SEBS was consistent with Webster et al. (2016), with a strong sensitivity to $T_{S}, T_{A}$, and $\delta$ and weak sensitivity to $P_{v a p}$ (Fig. 6). The sensitivity to $U_{x}$ was comparatively weaker among inputs compared to Webster et al. (2016) but is likely the result of individual land unit input perturbation rather than distinct scene-wide 2 standard deviation input shifts. Our analysis contrasted the SEBS meteorological sensitivity analyses conducted by Elhag (2016) where there was a significant effect for relative humidity, strongly associated with $P_{v a p}$. Overall, the reduction in sensitivity exhibited by SEBSER was attributed to the mitigating effect of the domain based energy restraint from the collection of $30 \times 30 \mathrm{~m}$ land units throughout the Landsat scene. This effect contrasted the direct approach inherent in SEBS, where the derivation of $\lambda E$ was specific and isolated to each $30 \times 30 m$ land unit (Su, 2002). This also explained the residual $\lambda E$ variation in the sensitivity distribution plots (Fig. 6), another important point of difference between SEBS and SEBS-ER in this study. SEBS applications are affected by input error and bias for a selected area of interest, while SEBS-ER applications are affected by input error and bias for the entire Landsat scene. This reinforces the importance of confirming SEBS-ER's utility over alternative domains and spatial resolutions than that of a multispectral Landsat 5 or 7 product.

\subsection{Validation and Performance of SEBS and SEBS-ER}

SEBS-ER reduced the RMSE of $\lambda E$ estimates compared to SEBS, HTEM, and S-SEBI surface energy balance algorithms, when compared to two independent eddy covariance flux towers (Table 2). Also, among all flux tower comparisons, SEBS-ER showed a significant improvement compared to SEBS in $\lambda E$ accuracy (Table 3). The difference in the $\lambda E$ estimates at Tumbarumba were noticeably smaller and more consistent with SEBS-ER compared to SEBS (Fig. 8 and Table 2), particularly for a forested area with a $40 \mathrm{~m}$ canopy (Leuning, 2002). Furthermore, the underestimation of $\lambda E$ by SEBS-ER on the 1 Sep 2007 was likely attributed to the high density of land units along the cold and wet edge of the SHT density plot, caused from variation within $R_{A H}$ data and the confounding effect of widespread snow 
cover within the alpine areas of the Canberra study area (Fig. 1). Within SEBS-ER, these sharp and distinct changes in land type and their subsequent influence on $T_{S}$ may also lead to discontinuities and separations within the $S H T$, preventing the image search algorithm from correctly identifying $S H R_{\min }$ and $S H R_{\max }$. Similarly, the choice of interpolation method for $U_{x}$ should be strongly considered, given its strong variability and influential effect on $S H R$ through SEBS $R_{A H}$ and $H$ (Webster et al., 2016). This consideration of $T_{S}$ and $U_{x}$ discontinuities is an added complexity of SEBS-ER that is not currently required by SEBS (Su, 2002). Further development and validation is required if SEBS-ER is to be applied among land types other than the wet sclerophyll forest (van Gorsel et al., 2013) and sub alpine grassland assessed in this study (Leuning, 2002).

The low RMSE of SEBS-ER at the Nimmo High Plains flux tower was very positive (Table 2), given it relied on all land units within the Landsat scene for the energy restraint and that these land units were masked by cloud contamination, affected by topographic influences (McVicar et al., 2007; Webster et al., 2016), and representative of heterogeneous land covers and vegetation heights (Webster et al., 2016). The $32.2 \mathrm{~W} \mathrm{~m}^{-2}$ RMSE of SEBSER at the sub-alpine grassland flux tower was less than that reported by $\mathrm{Su}$ et al. (2007) (61 $W^{-2}$ ) for grassland and needle-leaf forest sites, less than that reported by $\mathrm{Su}$ et al. (2005) for maize and soybean $\left(51 \mathrm{~W} \mathrm{~m}^{-2}\right)$, and less than that reported by Yang et al. (2010) in maize $\left(80 \mathrm{~W} \mathrm{~m}^{-2}\right)$ and wheat $\left(51 \mathrm{~W} \mathrm{~m}^{-2}\right)$. Limited to the comparison of the two flux towers, SEBS-ER had higher accuracy in $\lambda E$ estimates, compared to those obtained from SEBS in this study and others.

\subsection{Temporal Stability of SEBS and SEBS-ER}

SEBS-ER also had improved temporal stability compared to SEBS, reflected in reduced RMSE across land types and seasons, compared to an independent daily PT-JPL dataset (Fig. 10). Overall, the SEBS algorithm underestimated $H$ as a result of inaccuracies and limitations within the derivation of the $T_{A}, T_{S}$, and $R_{A H}$ spatial grids. These limitations resulted in an overestimation of $\lambda E$ which led to larger $E T_{a}$ values than modelled by PTJPL. SEBS-ER's scaling of sensible heat flux between $A E$ and the wet limit $\left(H_{w e t}\right)$ ensured that it was fitted to the range of available energies within the domain of land units present in the Landsat scene, leading to reduced $\lambda E$ and $E T_{a}$ estimations, more equivalent to those from PT-JPL. The scaling of $H$ by SEBS-ER was also attributed to the more favourable comparison to pan evaporation data (Fig. 11), where the SEBS-ER algorithm substantially reduced the overestimation of $E T_{a}$ over pan evaporation by SEBS, particular for smaller $E T_{a}$ 
estimates.

Increased temporal stability is an important factor in the estimation and application of $E T_{a}$ estimates (Baldocchi et al., 2001; Senay et al., 2011), particularly for hydrological modelling in water catchment areas (Immerzeel and Droogers, 2008). Additionally, current downscaling techniques (Hong et al., 2011; Singh et al., 2014) continue to open opportunities for fusions between low spatial resolution, high temporal resolution data and high spatial resolution, low temporal resolution data (Singh et al., 2014). The improvement in temporal stability in SEBS-ER, over SEBS (Fig. 10 and Fig. 11), suggests that SEBS-ER would provide more reliable high temporal and spatial estimates of $E T_{a}$ from such fused datasets. This would considerably help hydrological modelling and accounting in water catchment areas (Immerzeel and Droogers, 2008).

\section{Conclusion}

The integration of a domain based triangular energy restraint into the SEBS surface energy balance algorithm ( $\mathrm{Su}, 2002)$ was successful over two heterogeneous study areas in south-east Australia. The new approach, SEBS-ER, effectively produced surface energy balance flux components and $E T_{a}$ estimates with improved resilience to input error, significantly improved accuracy to flux tower references, and improved temporal stability, compared to daily PT-JPL data and pan evaporation measures. The SEBS-ER approach still needs to be tested in other ecosystems, across different geographic domains, and at different spatial scales, particularly in environments where the number of Landsat land units representative of extreme hot and dry or cold and wet conditions are relatively small. These current limitations arise because the SEBS-ER triangular search and energy restraint is static and does not respond to varying numbers of land units on either edge of the $S H T$ or adapt to alternative geographic domains and sensor resolutions.

The added triangular energy restraint is novel in its use of surface energy balance flux components and the limitation imposed by $H_{\text {wet }}$ to constrain $H$ and $\lambda E$ using $S H R$. Further, SEBS-ER can largely mitigate the complex errors and uncertainties within remotely sensed, meteorological, and land type inputs to produce more reliable and accurate spatially distributed $E T_{a}$ products. Continued improvements to the accuracy and reliability of exiting SEB algorithms, demonstrated by SEBS-ER, are a valuable contribution towards future research and the practical measurement of spatially distributed $E T_{a}$, particularly given the continued investment and commitment in medium resolution multispectral satellite platforms 
with thermal infrared (Landsat 8, Landsat 9, Sentinel-3).

\section{Acknowledgments}

We thank the Sydney Catchment Authority, particularly Alan Benson for his coordination, for supporting this research through an Australian Research Council Linkage Grant (LP0990137). This work was supported by the Centre for Ecosystem Science, UNSW Australia. Landsat Surface Reflectance products were provided courtesy of the U.S. Geological Survey Earth Resources Observation and Science Center. We would also like to thank the Editor and four anonymous reviewers for their feedback, which substantially improved the manuscript.

\section{References}

Agam, N., Kustas, W. P., Anderson, M. C., Li, F., and Neale, C. M. (2007). A vegetation index based technique for spatial sharpening of thermal imagery. Remote Sensing of Environment, 107(4):545-558.

Allen, R., Irmak, A., Trezza, R., Hendrickx, J. M., Bastiaanssen, W., and Kjaersgaard, J. (2011a). Satellite-based et estimation in agriculture using SEBAL and METRIC. Hydrological Processes, 25(26):4011-4027.

Allen, R. G., Burnett, B., Kramber, W., Huntington, J., Kjaersgaard, J., Kilic, A., Kelly, C., and Trezza, R. (2013). Automated calibration of the METRIC-Landsat evapotranspiration process. JAWRA Journal of the American Water Resources Association, 49(3):563-576.

Allen, R. G., Pereira, L. S., Howell, T. A., and Jensen, M. E. (2011b). Evapotranspiration information reporting: I. factors governing measurement accuracy. Agricultural Water Management, 98(6):899-920.

Allen, R. G., Pereira, L. S., Raes, D., Smith, M., et al. (1998). Crop evapotranspirationguidelines for computing crop water requirements-fao irrigation and drainage paper 56 . FAO, Rome, 300(9):D05109.

Allen, R. G., Tasumi, M., and Trezza, R. (2007). Satellite-based energy balance for mapping evapotranspiration with internalized calibration (METRIC) - Model. Journal of irrigation and drainage engineering, 133(4):380-394. 
Anderson, M. C., Allen, R. G., Morse, A., and Kustas, W. P. (2012). Use of landsat thermal imagery in monitoring evapotranspiration and managing water resources. Remote Sensing of Environment, 122:50-65.

Baldocchi, D., Falge, E., Gu, L., Olson, R., et al. (2001). Fluxnet: A new tool to study the temporal and spatial variability of ecosystem-scale carbon dioxide, water vapor, and energy flux densities. Bulletin of the American Meteorological Society, 82(11):2415.

Bastiaanssen, W., Menenti, M., Feddes, R., and Holtslag, A. (1998). A remote sensing surface energy balance algorithm for land (sebal). 1. formulation. Journal of hydrology, 212:198-212.

Berk, A., Anderson, G. P., Bernstein, L. S., Acharya, P. K., Dothe, H., Matthew, M. W., Adler-Golden, S. M., Chetwynd Jr, J. H., Richtsmeier, S. C., Pukall, B., et al. (1999). MODTRAN4 radiative transfer modeling for atmospheric correction. In SPIE's International Symposium on Optical Science, Engineering, and Instrumentation, pages 348-353. International Society for Optics and Photonics.

Brutsaert, W. (1999). Aspects of bulk atmospheric boundary layer similarity under freeconvective conditions. Reviews of geophysics, 37(4):439-451.

Carlson, T. (2007). An overview of the" triangle method" for estimating surface evapotranspiration and soil moisture from satellite imagery. Sensors, 7(8):1612-1629.

Carlson, T. N. (1986). Regional-scale estimates of surface moisture availability and thermal inertia using remote thermal measurements. Remote Sensing Reviews, 1(2):197-247.

Cesaraccio, C., Spano, D., Duce, P., and Snyder, R. L. (2001). An improved model for determining degree-day values from daily temperature data. International Journal of Biometeorology, 45(4):161-169.

Chen, Y., Xia, J., Liang, S., Feng, J., Fisher, J. B., Li, X., Li, X., Liu, S., Ma, Z., Miyata, A., et al. (2014). Comparison of satellite-based evapotranspiration models over terrestrial ecosystems in China. Remote Sensing of Environment, 140:279-293.

Chiew, F. H. S. and McMahon, T. A. (2002). Modelling the impacts of climate change on australian streamflow. Hydrological Processes, 16(6):1235-1245. 
Daly, C. (2006). Guidelines for assessing the suitability of spatial climate data sets. International journal of climatology, 26(6):707-721.

Donlon, C., Berruti, B., Buongiorno, A., Ferreira, M.-H., Féménias, P., Frerick, J., Goryl, P., Klein, U., Laur, H., Mavrocordatos, C., et al. (2012). The global monitoring for environment and security (GMES) sentinel-3 mission. Remote Sensing of Environment, 120:37-57.

Elhaddad, A. and Garcia, L. A. (2014). Using a surface energy balance model (ReSETRaster) to estimate seasonal crop water use for large agricultural areas: Case study of the Palo Verde irrigation district. Journal of Irrigation and Drainage Engineering, 140(10).

Elhag, M. (2016). Inconsistencies of sebs model output based on the model inputs: Global sensitivity contemplations. Journal of the Indian Society of Remote Sensing, pages 1-8.

Evett, S. R., Kustas, W. P., Gowda, P. H., Anderson, M. C., Prueger, J. H., and Howell, T. A. (2012). Overview of the Bushland Evapotranspiration and Agricultural Remote sensing EXperiment 2008 (BEAREX08): A field experiment evaluating methods for quantifying ET at multiple scales. Advances in Water Resources, 50:4-19.

Fisher, J. B., Tu, K. P., and Baldocchi, D. D. (2008). Global estimates of the landatmosphere water flux based on monthly avhrr and islscp-ii data, validated at 16 fluxnet sites. Remote Sensing of Environment, 112(3):901-919.

Gallant, J., Dowling, T., Read, A., Wilson, N., and Tickle, P. (2011). 1 second SRTM Level 2 Derived Smoothed Digital Elevation Model (DEM-S) Version 1. Technical report, Geoscience Australia, Canberra.

Gampe, D., Ludwig, R., Qahman, K., and Afifi, S. (2016). Applying the Triangle Method for the parameterization of irrigated areas as input for spatially distributed hydrological modelingAssessing future drought risk in the Gaza Strip (Palestine). Science of The Total Environment, 543:877-888.

Garratt, J. and Hicks, B. (1973). Momentum, heat and water vapour transfer to and from natural and artificial surfaces. Quarterly Journal of the Royal Meteorological Society, 99(422):680-687. 
Gibson, L., Münch, Z., and Engelbrecht, J. (2011). Particular uncertainties encountered in using a pre-packaged SEBS model to derive evapotranspiration in a heterogeneous study area in South Africa. Hydrology and Earth System Sciences, 15(1):295-310.

Glenn, E. P., Doody, T. M., Guerschman, J. P., Huete, A. R., King, E. A., McVicar, T. R., Van Dijk, A. I., Van Niel, T. G., Yebra, M., and Zhang, Y. (2011). Actual evapotranspiration estimation by ground and remote sensing methods: the australian experience. Hydrological Processes, 25(26):4103-4116.

Gokmen, M., Vekerdy, Z., Verhoef, A., Verhoef, W., Batelaan, O., and van der Tol, C. (2012). Integration of soil moisture in SEBS for improving evapotranspiration estimation under water stress conditions. Remote Sensing of Environment, 121:261 - 274.

Han, L., Wang, P., Yang, H., Liu, S., and Wang, J. (2006). Study on ndvi-t s space by combining lai and evapotranspiration. Science in China Series D, 49(7):747-754.

Hong, S.-h., Hendrickx, J. M., and Borchers, B. (2011). Down-scaling of sebal derived evapotranspiration maps from modis $(250 \mathrm{~m})$ to landsat $(30 \mathrm{~m})$ scales. International journal of remote sensing, 32(21):6457-6477.

Huete, A., Didan, K., Miura, T., Rodriguez, E. P., Gao, X., and Ferreira, L. G. (2002). Overview of the radiometric and biophysical performance of the modis vegetation indices. Remote sensing of environment, 83(1):195-213.

Immerzeel, W. and Droogers, P. (2008). Calibration of a distributed hydrological model based on satellite evapotranspiration. Journal of Hydrology, 349(3):411-424.

Jones, E., Oliphant, T., and Peterson, P. (2014). SciPy: Open source scientific tools for Python. Technical report, Scipy.org.

Kalma, J. D., McVicar, T. R., and McCabe, M. F. (2008). Estimating land surface evaporation: A review of methods using remotely sensed surface temperature data. Surveys in Geophysics, 29(4-5):421-469.

Keith, D. A. (2004). Ocean shores to desert dunes: the native vegetation of NSW and the ACT (Selected Extracts). Department of Environment and Conservation (NSW). 
Knipper, K. R., Kinoshita, A. M., and Hogue, T. S. (2016). Evaluation of a moderate resolution imaging spectroradiometer triangle-based algorithm for evapotranspiration estimates in subalpine regions. Journal of Applied Remote Sensing, 10(1):016002-016002.

Kustas, W. P. and Norman, J. M. (1997). A two-source approach for estimating turbulent fluxes using multiple angle thermal infrared observations. Water Resources Research, 33(6):1495-1508.

Leuning, R. (2002). Ozflux: An integrated program to study cycles of water and carbon in australian terrestrial systems/leuning r., et al. In Proc. 2nd Intern. Workshop on Advanced Flux Network and Flux Evaluation, Jeju, AsiaF-lux, page 5.

Li, Z.-L., Tang, B.-H., Wu, H., Ren, H., Yan, G., Wan, Z., Trigo, I. F., and Sobrino, J. A. (2013). Satellite-derived land surface temperature: Current status and perspectives. Remote Sensing of Environment, 131:14 - 37.

Lian, J. and Huang, M. (2016). Comparison of three remote sensing based models to estimate evapotranspiration in an oasis-desert region. Agricultural Water Management, 165:153162.

Liang, S., Zhongxin, C., and Zhiwei, J. (2014). Estimation of regional evapotranspiration over the southern great plains based on penman-monteith theory and the soil moisture estimates. In Agro-geoinformatics (Agro-geoinformatics 2014), Third International Conference on, pages $1-5$. IEEE.

Liaqat, U. W. and Choi, M. (2015). Surface energy fluxes in the northeast Asia ecosystem: SEBS and METRIC models using Landsat satellite images. Agricultural and Forest Meteorology, 214215:60 - 79.

Long, D. and Singh, V. P. (2012). A two-source trapezoid model for evapotranspiration (ttme) from satellite imagery. Remote Sensing of Environment, 121:370-388.

Long, D. and Singh, V. P. (2013). Assessing the impact of end-member selection on the accuracy of satellite-based spatial variability models for actual evapotranspiration estimation. Water Resources Research, 49(5):2601-2618.

Long, D., Singh, V. P., and Scanlon, B. R. (2012). Deriving theoretical boundaries to address scale dependencies of triangle models for evapotranspiration estimation. Journal of Geophysical Research: Atmospheres, 117(D5). 
Masek, J., Vermote, E., Saleous, N., Wolfe, R., Hall, F., Huemmrich, K., Gao, F., Kutler, J., and Lim, T.-K. (2006). A landsat surface reflectance dataset for north america, 1990-2000. Geoscience and Remote Sensing Letters, IEEE, 3(1):68-72.

McCabe, M. F. and Wood, E. F. (2006). Scale influences on the remote estimation of evapotranspiration using multiple satellite sensors. Remote Sensing of Environment, 105(4):271285.

McMahon, T., Peel, M., Lowe, L., Srikanthan, R., and McVicar, T. (2013). Estimating actual, potential, reference crop and pan evaporation using standard meteorological data: a pragmatic synthesis. Hydrology and Earth System Sciences, 17(4):1331-1363.

McVicar, T. R., Roderick, M. L., Donohue, R. J., Li, L. T., Van Niel, T. G., Thomas, A., Grieser, J., Jhajharia, D., Himri, Y., Mahowald, N. M., et al. (2012). Global review and synthesis of trends in observed terrestrial near-surface wind speeds: Implications for evaporation. Journal of Hydrology, 416:182-205.

McVicar, T. R., Van Niel, T. G., Li, L., Hutchinson, M. F., Mu, X., and Liu, Z. (2007). Spatially distributing monthly reference evapotranspiration and pan evaporation considering topographic influences. Journal of hydrology, 338(3):196-220.

Merz, R., Parajka, J., and Blöschl, G. (2011). Time stability of catchment model parameters: Implications for climate impact analyses. Water Resources Research, 47(2).

Monteith, J. L., editor (1965). Evaporation and environment, volume 19 of 205-23.

Mu, Q., Zhao, M., and Running, S. W. (2011). Improvements to a modis global terrestrial evapotranspiration algorithm. Remote Sensing of Environment, 115(8):1781-1800.

Petropoulos, G., Carlson, T. N., and Wooster, M. J. (2009a). An overview of the use of the simsphere soil vegetation atmosphere transfer (SVAT) model for the study of landatmosphere interactions. Sensors, 9(6):4286-4308.

Petropoulos, G., Wooster, M., Carlson, T., Kennedy, M., and Scholze, M. (2009b). A global bayesian sensitivity analysis of the 1d simsphere soil-vegetation-atmospheric transfer (SVAT) model using gaussian model emulation. Ecological Modelling, 220(19):24272440. 
Price, J. C. (1990). Using spatial context in satellite data to infer regional scale evapotranspiration. Geoscience and Remote Sensing, IEEE Transactions on, 28(5):940-948.

Priestley, C. and Taylor, R. (1972). On the assessment of surface heat flux and evaporation using large-scale parameters. Monthly weather review, 100(2):81-92.

Roerink, G., Su, Z., and Menenti, M. (2000). S-sebi: A simple remote sensing algorithm to estimate the surface energy balance. Physics and Chemistry of the Earth, Part B: Hydrology, Oceans and Atmosphere, 25(2):147 - 157.

Roy, D., Wulder, M., Loveland, T., C.E., W., Allen, R., Anderson, M., Helder, D., Irons, J., Johnson, D., Kennedy, R., Scambos, T., Schaaf, C., Schott, J., Sheng, Y., Vermote, E., Belward, A., Bindschadler, R., Cohen, W., Gao, F., Hipple, J., Hostert, P., Huntington, J., Justice, C., Kilic, A., Kovalskyy, V., Lee, Z., Lymburner, L., Masek, J., McCorkel, J., Shuai, Y., Trezza, R., Vogelmann, J., Wynne, R., and Zhu, Z. (2014). Landsat-8: Science and product vision for terrestrial global change research. Remote Sensing of Environment, $145: 154-172$.

Rwasoka, D., Gumindoga, W., and Gwenzi, J. (2011). Estimation of actual evapotranspiration using the Surface Energy Balance System (SEBS) algorithm in the Upper Manyame catchment in Zimbabwe. Physics and Chemistry of the Earth, Parts A/B/C, 36(14):736746.

Scarth, P. (2014). Continental scale forest and woodland structure mapping using landsat, alos palsar and glas icesat. In ForestSAT2014 Open Conference System.

Scarth, P., Phinn, S., and McAlpine, C. (2001). Integrating high and moderate spatial resolution image data to estimate forest age structure. Canadian Journal of Remote Sensing, 27(2):129-142.

Senay, G. B., Budde, M. E., and Verdin, J. P. (2011). Enhancing the simplified surface energy balance (SSEB) approach for estimating landscape et: Validation with the metric model. Agricultural Water Management, 98(4):606-618.

Simpson, R. (2012). Nimmo high plains ozflux tower site ozflux: Australian and new zealand flux research and monitoring. hdl: 102.100.100/14220. 
Singh, R. K., Senay, G. B., Velpuri, N. M., Bohms, S., and Verdin, J. P. (2014). On the downscaling of actual evapotranspiration maps based on combination of modis and landsat-based actual evapotranspiration estimates. Remote Sensing, 6(11):10483-10509.

Su, H., McCabe, M., Wood, E., Su, Z., and Prueger, J. (2005). Modeling evapotranspiration during smacex: Comparing two approaches for local-and regional-scale prediction. Journal of hydrometeorology, 6(6):910-922.

Su, H., Wood, E., McCabe, M., and Su, Z. (2007). Evaluation of remotely sensed evapotranspiration over the ceop eop-1 reference sites. Meteorological society of Japan, 85:439-459.

Su, Z. (2002). The surface energy balance system (sebs) for estimation of turbulent heat fluxes. Hydrology and Earth System Sciences Discussions, 6(1):85-100.

Sun, H. (2016). Two-stage trapezoid: A new interpretation of the land surface temperature and fractional vegetation coverage space. IEEE JOURNAL OF SELECTED TOPICS IN APPLIED EARTH OBSERVATIONS AND REMOTE SENSING, 9(1):336-346.

Tang, R., Li, Z.-L., Jia, Y., Li, C., Sun, X., Kustas, W. P., and Anderson, M. C. (2011). An intercomparison of three remote sensing-based energy balance models using large aperture scintillometer measurements over a wheat-corn production region. Remote Sensing of Environment, 115(12):3187-3202.

Tang, R., Li, Z.-L., and Tang, B. (2010). An application of the t s-vi triangle method with enhanced edges determination for evapotranspiration estimation from modis data in arid and semi-arid regions: Implementation and validation. Remote Sensing of Environment, 114(3):540-551.

Tian, J., Su, H., Sun, X., Chen, S., He, H., and Zhao, L. (2013). Impact of the spatial domain size on the performance of the ts-vi triangle method in terrestrial evapotranspiration estimation. Remote Sensing, 5(4):1998-2013.

Timmermans, J., Su, Z., Tol, C., Verhoef, A., and Verhoef, W. (2013). Quantifying the uncertainty in estimates of surface-atmosphere fluxes through joint evaluation of the sebs and scope models. Hydrology and earth system sciences, 17(4):1561-1573.

USGS, L. D. (2009). MOD13Q1. USGS/Earth Resources Observation and Science (EROS) Center, Sioux Falls, South Dakota. 
van Gorsel, E., Berni, J., Briggs, P., Cabello-Leblic, A., Chasmer, L., Cleugh, H., Hacker, J., Hantson, S., Haverd, V., Hughes, D., and et al. (2013). Primary and secondary effects of climate variability on net ecosystem carbon exchange in an evergreen eucalyptus forest. Agricultural and Forest Meteorology, 182183:248 - 256.

Van Niel, T. G., McVicar, T. R., Roderick, M. L., van Dijk, A. I., Beringer, J., Hutley, L. B., and Van Gorsel, E. (2012). Upscaling latent heat flux for thermal remote sensing studies: Comparison of alternative approaches and correction of bias. Journal of Hydrology, 468:35-46.

Van Niel, T. G., McVicar, T. R., Roderick, M. L., van Dijk, A. I., Renzullo, L. J., and Van Gorsel, E. (2011). Correcting for systematic error in satellite-derived latent heat flux due to assumptions in temporal scaling: Assessment from flux tower observations. Journal of Hydrology, 409(1):140-148.

Vanwalleghem, T. and Meentemeyer, R. (2009). Predicting forest microclimate in heterogeneous landscapes. Ecosystems, 12(7):1158-1172.

Wang, X.-G., Wang, W., Huang, D., Yong, B., and Chen, X. (2014). Modifying sebal model based on the trapezoidal relationship between land surface temperature and vegetation index for actual evapotranspiration estimation. Remote Sensing, 6(7):5909.

Webster, E., Ramp, D., and Kingsford, R. T. (2016). Spatial sensitivity of surface energy balance algorithms to meteorological data in a heterogeneous environment. Remote Sensing of Environment, 187:294 - 319 .

Winsemius, H., Schaefli, B., Montanari, A., and Savenije, H. (2009). On the calibration of hydrological models in ungauged basins: A framework for integrating hard and soft hydrological information. Water Resources Research, 45(12).

Yang, D., Chen, H., and Lei, H. (2010). Estimation of evapotranspiration using a remote sensing model over agricultural land in the north china plain. International Journal of Remote Sensing, 31(14):3783-3798.

Yang, Y. and Shang, S. (2013). A hybrid dual-source scheme and trapezoid frameworkbased evapotranspiration model (HTEM) using satellite images: Algorithm and model test. Journal of Geophysical Research: Atmospheres, 118(5):2284-2300. 
Yao, Y., Liang, S., Cheng, J., Liu, S., Fisher, J. B., Zhang, X., Jia, K., Zhao, X., Qin, Q., Zhao, B., et al. (2013). Modis-driven estimation of terrestrial latent heat flux in china based on a modified priestley-taylor algorithm. Agricultural and forest meteorology, $171: 187-202$.

Yin, J., Zhan, C., Wang, H., and Wang, F. (2016). Integration of remote sensing evapotranspiration (et) model and hydrologic model for mapping daily et time-series at river basin scale. Hydrology Research, page nh2016165.

Zhang, L., Potter, N., Hickel, K., Zhang, Y., and Shao, Q. (2008a). Water balance modeling over variable time scales based on the budyko framework-model development and testing. Journal of Hydrology, 360(1):117-131.

Zhang, R., Tian, J., Su, H., Sun, X., Chen, S., and Xia, J. (2008b). Two improvements of an operational two-layer model for terrestrial surface heat flux retrieval. Sensors, 8(10):61656187.

\section{Appendix A}

\section{A.1. Data sources and preprocessing}

Atmospherically corrected shortwave Landsat data were obtained from the United States Geological Survey (USGS) Earth Resources Observation and Science (EROS) Center Science Processing Architecture On Demand Interface (EPSG) (espa.cr.usgs.gov). These data consisted of visible and near infrared surface reflectance bands, a thermal radiance band, and precalculated vegetation indices (Masek et al., 2006). Landsat thermal data was atmospherically corrected using MODTRAN model (Berk et al., 1999), narrowband transmissivity, path radiance, and sky radiance values are listed for each Landsat acquisition date in the Canberra (Table A1) and Sydney (Table A2) study areas. In addition to the Landsat data, Bureau of Meteorology (BOM) minimum temperature $\left(T_{M},{ }^{\circ} C\right)$, maximum temperature $\left(T_{X},{ }^{\circ} C\right), U_{x}$, air pressure $\left(P_{a i r}, k P a\right), P_{v a p}$, and $\delta$ data were collated for use from a spatial subset of BOM ground stations within a $100 \mathrm{~km}$ buffer of each respective study area (Fig. 1). $U_{x}, P_{a i r}$, and $P_{v a p}$ stations were additionally subset to those with at least six observations for the respective Landsat acquisition day. Elevation data were sourced from the shuttle radar topography mission (SRTM) (Gallant et al., 2011) and vegetation height data were obtained from a 2009 Australian dataset (Scarth et al., 2001) that combined ALOS-1 PALSAR, Landsat, and ICESat/GLAS data. 
To complement the temporal (Fig. 2b) and spatial (Fig. 1) extent of the Landsat data in the Sydney study area, the MOD13Q1 product (USGS, 2009) from the Moderate Resolution Imaging Spectrometer (MODIS) were obtained for use in the PT-JPL algorithm (Fisher et al., 2008). Data was acquired from the USGS Land Processes Distributed Active Archive Center (LP DAAC) and the $250 m 16$ day average Normalized Difference Vegetation Index (NDVI) images were extracted from the MOD13Q1 archive and reprojected to the UTM $55 \mathrm{~N}$ map projection of the Landsat data. Daily BOM $T_{M}, T_{X}, \delta, P_{v a p}$, and $P_{\text {sat }}$ data were also collated for use in the PT-JPL algorithm. Station data within a $100 \mathrm{~km}$ buffer of the Sydney study area (Fig. 1) were selected for use. $P_{\text {vap }}$ and $P_{\text {sat }}$ data were additionally subset to those stations with at least six observations for each respective day.

Table A1: Atmospheric correction parameters (Transmissivity $\tau_{N B}$, Path Radiance $R_{P}$ and Downwelling Radiance $R_{S K Y}$ ) obtained using MODTRAN (Berk et al., 1999) for Landsat thermal data in the Canberra study area (Fig. 1).

\begin{tabular}{llll}
\hline Acquisition Date & $\tau_{N B}$ & $R_{P}$ & $R_{S K Y}$ \\
\hline 17 Nov 2006 & 0.92 & 0.50 & 0.89 \\
05 Feb 2007 & 0.78 & 1.68 & 2.74 \\
09 Mar 2007 & 0.92 & 0.53 & 0.93 \\
26 Apr 2007 & 0.93 & 0.43 & 0.75 \\
12 May 2007 & 0.91 & 0.59 & 1.02 \\
01 Sep 2007 & 0.95 & 0.27 & 0.49 \\
16 Oct 2008 & 0.94 & 0.41 & 0.75 \\
26 Apr 2001 & 0.88 & 0.86 & 1.49 \\
29 Jun 2001 & 0.90 & 0.69 & 1.19 \\
\hline
\end{tabular}


Table A2: Atmospheric correction parameters (Transmissivity $\tau_{N B}$, Path Radiance $R_{P}$ and Downwelling Radiance $R_{S K Y}$ ) obtained using MODTRAN (Berk et al., 1999) for Landsat thermal data in the Sydney study area (Fig. 1).

\begin{tabular}{|c|c|c|c|}
\hline Acquisition Date & $\tau_{N B}$ & $R_{P}$ & $R_{S K Y}$ \\
\hline 01 Dec 1999 & 0.83 & 1.2 & 2.04 \\
\hline 03 Feb 2000 & 0.83 & 1.31 & 2.23 \\
\hline 09 May 2000 & 0.9 & 0.69 & 1.18 \\
\hline $12 \mathrm{Jul} 2000$ & 0.95 & 0.33 & 0.58 \\
\hline 14 Sep 2000 & 0.92 & 0.56 & 0.97 \\
\hline 16 Oct 2000 & 0.91 & 0.55 & 0.96 \\
\hline 26 Apr 2001 & 0.85 & 0.99 & 1.69 \\
\hline 29 Jun 2001 & 0.9 & 0.64 & 1.08 \\
\hline $31 \mathrm{Jul} 2001$ & 0.9 & 0.64 & 1.08 \\
\hline 08 Feb 2002 & 0.75 & 1.82 & 2.97 \\
\hline 12 Mar 2002 & 0.74 & 1.82 & 2.95 \\
\hline 13 Apr 2002 & 0.81 & 1.42 & 2.34 \\
\hline 16 Jun 2002 & 0.86 & 0.91 & 1.53 \\
\hline $02 \mathrm{Jul} 2002$ & 0.93 & 0.46 & 0.78 \\
\hline $18 \mathrm{Jul} 2002$ & 0.93 & 0.45 & 0.79 \\
\hline 04 Sep 2002 & 0.89 & 0.76 & 1.3 \\
\hline 22 Oct 2002 & 0.94 & 0.39 & 0.72 \\
\hline 07 Nov 2002 & 0.94 & 0.45 & 0.82 \\
\hline 26 Jan 2003 & 0.82 & 1.47 & 2.46 \\
\hline 16 Apr 2003 & 0.93 & 0.48 & 0.83 \\
\hline $13 \mathrm{Jul} 2003$ & 0.91 & 0.54 & 0.93 \\
\hline 15 Sep 2003 & 0.91 & 0.52 & 0.9 \\
\hline 04 Dec 2003 & 0.73 & 2.01 & 3.27 \\
\hline 09 Mar 2004 & 0.74 & 1.96 & 3.19 \\
\hline 29 Jun 2004 & 0.9 & 0.64 & 1.09 \\
\hline $15 \mathrm{Jul} 2004$ & 0.91 & 0.54 & 0.92 \\
\hline $31 \mathrm{Jul} 2004$ & 0.93 & 0.41 & 0.71 \\
\hline 17 Sep 2004 & 0.9 & 0.68 & 1.16 \\
\hline 03 Oct 2004 & 0.87 & 0.88 & 1.5 \\
\hline 22 Dec 2004 & 0.85 & 1.11 & 1.92 \\
\hline 07 Jan 2005 & 0.95 & 0.31 & 0.57 \\
\hline 08 Feb 2005 & 0.8 & 1.41 & 2.42 \\
\hline 24 Feb 2005 & 0.79 & 1.65 & 2.71 \\
\hline 12 Mar 2005 & 0.84 & 1.28 & 2.13 \\
\hline $18 \mathrm{Jul} 2005$ & 0.92 & 0.46 & 0.79 \\
\hline 16 Apr 2006 & 0.93 & 0.45 & 0.78 \\
\hline 05 Jul 2006 & 0.86 & 0.83 & 1.4 \\
\hline 22 Aug 2006 & 0.92 & 0.51 & 0.88 \\
\hline 23 Sep 2006 & 0.91 & 0.59 & 1.04 \\
\hline 09 Oct 2006 & 0.96 & 0.24 & 0.45 \\
\hline 10 Nov 2006 & 0.89 & 0.76 & 1.31 \\
\hline 28 Dec 2006 & 0.83 & 1.25 & 2.12 \\
\hline 29 Jan 2007 & 0.84 & 1.15 & 1.95 \\
\hline 05 May 2007 & 0.86 & 0.98 & 1.63 \\
\hline 22 Jun 2007 & 0.94 & 0.33 & 0.58 \\
\hline 10 Sep 2007 & 0.88 & 0.76 & 1.32 \\
\hline 04 Mar 2008 & 0.83 & 1.23 & 2.05 \\
\hline 20 Mar 2008 & 0.81 & 1.44 & 2.39 \\
\hline 28 Sep 2008 & 0.86 & 1.02 & 1.72 \\
\hline 18 Jan 2009 & 0.87 & 0.96 & 1.64 \\
\hline $21 \mathrm{Jan} 2010$ & 0.8 & 1.44 & 2.42 \\
\hline 22 Feb 2010 & 0.69 & 2.39 & 3.82 \\
\hline 26 Mar 2010 & 0.79 & 1.63 & 2.68 \\
\hline
\end{tabular}




\section{Appendix B}

\section{B.1. Sensible Heat Triangle image processing routine}

To objectively identify the boundaries of the Sensible Heat Triangle $(S H T)$, we first determined the domain range of the $S H T$ using histograms of $S H R$ and $E V I$ to determine the horizontal $\left(S H R_{1 D M A X}\right.$ and $\left.S H R_{1 D M I N}\right)$ and vertical $\left(E V I_{1 D M A X}\right.$ and $\left.E V I_{1 D M I N}\right)$ limits of the subsequent two dimensional density $S H T$ analysis. The $S H T$ limits were determined where:

- $S H R_{1 D M I N}$ was the lower $S H R$ where the bin count reached 1/15000 of the peak,

- $S H R_{1 D M A X}$ was the upper $S H R$ where the bin count reached $1 / 30000$ of the peak,

- $E V I_{1 D M I N}$ was the lower $E V I$ where the bin count reached $1 / 5000$ of the peak, and

- $E V I_{1 D M A X}$ was the upper $E V I$ where the bin count reached $1 / 5000$ of the peak.

The one dimensional density limits $\left(S H R_{1 D M I N}, S H R_{1 D M A X}, E V I_{1 D M I N}\right.$ and $\left.E V I_{1 D M A X}\right)$ were then used to produce the 2D SHT density distribution histogram, with $1200 S H R$ bins and 1000 EVI bins.

To isolate the horizontal and vertical limits of the SHT distribution, a nine cell 2D correlation filter (Jones et al., 2014) was then used to smooth and enhance the boundary of the density distribution. Then, a custom image search function was created to identify the horizontal and vertical edges of the $S H T$ using an iterative search routine that emanated from the peak density point within the 2D SHT density distribution (Fig. 4). The boundary pixels were then used to identify the left $\left(S H R_{M I N}\right)$, right $\left(S H R_{M A X}\right)$, top $\left(E V I_{M A X}\right)$ and bottom $\left(E V I_{M I N}\right)$ edges of the triangular SHT domain (Fig. 4). Through manual optimisation, the boundaries of the SHT were identified where:

- $E V I_{M I N}$ was the average of the lowest 48 boundary pixels,

- $E V I_{M A X}$ was the average of the highest 12 boundary pixels,

- $S H R_{M I N}$ was the average of the lowest 48 boundary pixels, and

- $S H R_{M A X}$ was the average of the highest 12 boundary pixels.

The number of boundary pixels for each $S H T$ limit were reflective of the number of horizontal and vertical bins used to construct the $S H T$ (1200 x 1000), the expectant shape of the $S H T$ density distribution (Fig. 4), and the relative domain and resolution of a Landsat tile with between 0 and 30 percent cloud contamination. 


\section{LIST OF FIGURE CAPTIONS}

- Figure 1: Two study areas in south-east Australia: a) the Sydney study area (Landsat tile (path 90, row 84)) contained two long term pan evaporation stations (squares with station IDs); and b) the Canberra study area (Landsat tile (path 91, row 85)), with the Tumbarumba (star T) and Nimmo High Plains (star N) eddy covariance flux towers. Dark grey diamonds were the meteorological ground stations used to source $T_{A}, U_{x}, P_{\text {vap }}$, and $P_{\text {air }}$ meteorological inputs for SEBS and SEBS-ER. The RS1 annotation indicates the location of the Wagga Wagga radiosonde station and the RS2 annotation indicates the location of the Sydney International airport radiosonde station. Coloured Shading showed relative height of the vegetation across south east Australia (Scarth, 2014). The WGS 84 coordinate grid was overlaid on top of the map UTM $55 \mathrm{~N}$ projection.

- Figure 2: a) Nine Landsat acquisition dates for the Canberra study area (Fig. 1) were used to test the sensitivity, resilience and accuracy of the SEBS and SEBS-ER surface energy balance algorithms. All nine Landsat acquisitions were from the Landsat 5 Thematic Mapper (TM) (blue). b) Fifty-two Landsat acquisition dates for the Sydney study area (Fig. 1) were used to test the temporal stability of the SEBS and SEBS-ER surface energy balance algorithms. The Landsat data (1 Dec 1999 - 16 Apr 2003) were acquired by the Landsat 7 ETM+ (red) while Landsat data from 13 Jul 2003 onwards were acquired by the Landsat 5 TM (blue).Precise acquisition dates ca be found within the atmospheric correction tables located in Appendix A.

- Figure 3: A flowchart depicting the two stage energy restraint incorporated into the Surface Energy Balance System. The first stage (orange shaded area) quantifies a global offset for surface temperature, while the second stage (blue shaded area) uses a domainbased image search routine to identify the limits of the Sensible Heat Ratio $(S H R)$ to make a gradient and offset correction to sensible heat flux $(H)$. The routine continues until the aerodynamic resistance and the gradient and offset correction parameters stabilise.

- Figure 4: The constraint and adjustment of the SEBS-ER Sensible Heat Triangle $(S H T)$, defined by $S H R_{M A X}$ and $S H R_{M I N}$ values and a gradient $\left(A_{E R}\right)$ and intercept $\left(B_{E R}\right)$ applied to adjust the input $S H T$ distribution (shaded grey) to a new $S H T$ with an $S H R$ ranged between 0 and 1 (dark striped). 
- Figure 5: Sensible Heat Triangles (SHT) showing the density distribution of the Sensible Heat Ratio $(S H R)$ to the Enhanced Vegetation Index (Vegetation Fraction) for a) 17 Nov 2006, b) 5 Feb 2007, c) 9 Mar 2007, d) 26 Apr 2007, e) 12 May 2007, f) 1 Sep 2007, g) 8 Dec 2008, h) 25 Jan 2009 and j) 26 Feb 2009, where darker colours indicated higher densities. The horizontal dashed lines were the derived upper and lower limits of vegetation cover, while the vertical dashed lines represented the derived upper and lower limits of evaporative energy.

- Figure 6: Temporally averaged comparisons of $\lambda E$ input sensitivity for i) SEBS and ii) SEBS-ER surface energy balance algorithms after perturbing different input variables: a) surface temperature $\left(T_{S}\right)$; b) air temperature $\left(T_{A}\right)$; c) daily solar exposure $\left.(\delta) ; \mathrm{d}\right)$ surface roughness $\left(Z_{O M}\right)$; e) wind speed $\left(U_{x}\right)$; and $\mathrm{f}$ ) vapour pressure $\left(P_{\text {vap }}\right)$, where darker shading represented higher densities. Linear regressions between the change in $\lambda E$ to the $\%$ change of each input parameter were represented by dashed black lines, with the gradient coefficient $(\mathrm{m})$ and $R^{2}$ statistic displayed at the top of each density plot.

- Figure 7: Temporally averaged spatial grids of $\lambda E$ sensitivity from perturbation in (i) SEBS and (ii) SEBS-ER input variables in the Canberra study area (black polygon). Grids show the relative spatial change in $\lambda E$ related to a $1 \%$ change in (a) surface temperature $\left(T_{S},{ }^{\circ} C\right)$, (b) air temperature $\left(T_{A},{ }^{\circ} C\right)$, (c) solar exposure $\left(\delta, M J d a y^{-1}\right)$, (d) surface roughness for momentum $\left(Z_{O M}, m\right)$, (e) wind speed $\left(U_{x}, m s-1\right)$, and (f) vapour pressure $\left(P_{v a p}, k P a\right)$. Note the scale change between $T_{S}, T_{A}$ and $\delta(0-7.5$ $\left.W m^{-2}\right)$ and $Z_{O M}, U_{x}$ and $P_{v a p}\left(0-2.5 W^{-2}\right)$. UTM Eastings and Northings were for Zone 55 North.

- Figure 8: $750 m$ radial samples of $\lambda E\left(W m^{-2}\right)$ ( \pm 2 SD) from S-SEBI and HTEM (Webster et al., 2016) and SEBS and SEBS-ER, compared to $\lambda E$ observed at the Tumbarumba flux tower (black) (Fig. 1) for the nine acquisition dates: (a) 17 Nov 2006; (b) 5 Feb 2007; (c) 9 Mar 2007; (d) 26 Apr 2007; (e) 12 May 2007; (f) 1 Sep 2007; (g) 8 Dec 2008; (h) 25 Jan 2009; and (j) 26 Feb 2009.

- Figure 9: $30 m$ radial samples of $\lambda E\left(W m^{-2}\right)$ ( \pm 2 SD) from S-SEBI and HTEM (Webster et al., 2016) and SEBS and SEBS-ER, compared to $\lambda E$ observed at the Nimmo High Plains flux tower (black) (Fig. 1) for three acquisition dates: (c) 9 Mar 2007; (e) 12 May 2007; and (f) 1 Sep 2007. 
- Figure 10: Multifaceted comparison of SEBS and SEBS-ER ET to daily PT-JPL $E T_{a}$ data, showing the temporal average root mean square error (RMSE) spatially $\left(m m d a y^{-1}\right)$ of (a) SEBS and (b) SEBS-ER and the comparisons of density distributions between PT-JPL $E T_{a}$ to (c) SEBS $E T_{a}$ and (d) SEBS-ER $E T_{a}$. Seasonal differences in SEBS and SEBS-ER $E T_{a}$, compared to PT-JPL $E T_{a}$ were captured in estimates of mean absolute error (MAE), $\left(m m d a y^{-1}\right)$ for acquisitions in (e) summer, (f) autumn, (g) winter, and (h) spring.

- Figure 11: Daily pan evaporation data $\left(m m\right.$ day $\left.^{-1}\right)$ from stations (x) 070014 and $(+)$ 070263 in the Sydney study area (Fig. 1) over a ten year period (Fig. 2b) compared to actual evapotranspiration $\left(E T_{a}, m m d a y^{-1}\right)$ from (a) SEBS and (b) SEBS-ER. The red shaded area indicates unrealistic estimates of SEBS and SEBS-ER $E T_{a}$ and the green shaded area indicates valid SEBS and SEBS-ER $E T_{a}$ estimates. 